\title{
Review \\ On the Use of PEDOT as a Catalytic Counter Electrode Material in Dye-Sensitized Solar Cells
}

\author{
Edoardo Marchini ${ }^{1}$, Stefano Caramori ${ }^{1, *}$, Carlo Alberto Bignozzi ${ }^{1}\left(\mathbb{D}\right.$ and Stefano Carli ${ }^{2}(\mathbb{C}$ \\ 1 Department of Chemical Pharmaceutical, Agrarian Sciences of the University of Ferrara, 44121 Ferrara, Italy; \\ mrcdrd@unife.it (E.M.); g4s@unife.it (C.A.B.) \\ 2 Center for Translational Neurophysiology, Istituto Italiano di Tecnologia, 44121 Ferrara, Italy; \\ stefano.carli@iit.it \\ * Correspondence: stefano.caramori@unife.it
}

Citation: Marchini, E.; Caramori, S.; Bignozzi, C.A.; Carli, S. On the Use of PEDOT as a Catalytic Counter Electrode Material in Dye-Sensitized Solar Cells. Appl. Sci. 2021, 11, 3795. https://doi.org/10.3390/app11093795

Academic Editor: Serena Arnaboldi

Received: 17 March 2021

Accepted: 20 April 2021

Published: 22 April 2021

Publisher's Note: MDPI stays neutral with regard to jurisdictional claims in published maps and institutional affiliations.

Copyright: (c) 2021 by the authors. Licensee MDPI, Basel, Switzerland. This article is an open access article distributed under the terms and conditions of the Creative Commons Attribution (CC BY) license (https:/ / creativecommons.org/licenses/by/ $4.0 /)$.

\begin{abstract}
Dye-sensitized solar cells (DSSCs) emerged in the early 1990s as a promising alternative to the classic silicon-based solar cell due to their unique combination of low cost, ease of fabrication, color palette for building integration, and high efficiency in indoor applications. This review article describes the fabrication and the properties of poly (3,4-ethylenedioxythiophene) (PEDOT)-based catalytic counter electrodes (CEs) for DSSCs. In particular, the electrochemical reactivity PEDOT CEs used in conjunction with alternative redox mediators for DSSCs is outlined. Among alternative redox shuttles, cobalt and copper complexes, as well as totally organic thiolate/disulfide, have been considered. Finally, PEDOT can also be used as a hole conductor material in electrolyte-free solid-state dye-sensitized solar cells. This review clearly shows that the progress in DSSCs development is strongly linked to the introduction of PEDOT as a new counter electrode material.
\end{abstract}

Keywords: dye-sensitized solar cells; PEDOT; alternative redox mediators; cobalt complexes; copper complexes

\section{Introduction}

Dye-sensitized solar cells (DSSCs), which were developed by Grätzel and O'Regan in the early 1990s [1], represent a regenerative photoelectrochemical device type characterized by unique properties, such as transparency, low production cost, capability to harvest the diffuse light, wide choice of color palette, building integration capabilities in both indoor and outdoor conditions [1-5]. DSSCs are considered among the new-generation photovoltaic technologies which aim at achieving power conversion efficiency (PCE) comparable with that of existing technologies, but with low cost per meter square, tunability in color and shape, transparency, flexibility, and roll-to-roll production. In particular, organic and hybrid solar cells are considered as an "emerging photovoltaic technologies" class. Dyesensitized solar cells (DSSCs) have gathered much attention due to their potential, such as low cost, feasibility, building integration, and scalability [6]. Other significant emerging technologies in this field are organic/polymer solar cells (OSC) and metal organic perovskite solar cells (PSC) $[7,8]$. Although PSCs are rapidly overcoming the efficiency record for hybrid photovoltaic technologies (up to $25 \%$ ), their long-term stability under real working conditions remains an issue [9]. In particular, PSCs suffer from severe instability upon exposure to atmospheric $\mathrm{O} 2$ and humidity, light, high temperature, and an intrinsic instability upon prolonged working conditions as a result of ion migration and interface degradation [10-12].

The optimization of the whole DSSC has been achieved over the last 30 years through dedicated research oriented towards each part of the device, i.e., dye sensitizers, redox mediators, and catalytic counter electrodes (CEs) [2]. In particular, CEs play the important role of regenerating the reduced form of the redox electrolyte, maintaining a steady-state concentration of reduced mediator, which is essential to intercept the photo-oxidized dye at 
the photoanode, preventing charge recombination. Since the early developments of DSSC in the 1990s, the iodine/iodide (i.e., $\mathrm{I}^{-} / \mathrm{I}_{3}{ }^{-}$) couple was the most universally used mediator to conduct charge across the liquid electrolyte. Platinum coated counter electrodes ensured excellent electrocatalysis toward the iodine/iodide couple, but at the beginning of the 2000s, researchers moved to the search for alternative, lower cost, and more abundant electrode materials [3,4]. One of the causes of limited DSSC stability was indeed identified in the reaction of the electrolyte with the platinum counter electrode (CE), which can lead to the dissolution of $\mathrm{Pt}$ from the substrate [13].

From this perspective, low-cost conductive polymers, such as poly(3,4-ethylenedioxythiophene) (PEDOT), which also play a prominent role as hole transporting layers in OSC and PSC architectures, have emerged to replace Pt-coated CEs in DSSCs, thanks to its high room-temperature conductivity and remarkable stability [5,14-16]. It was later found that PEDOT electrodes displayed excellent electrocatalytic behavior not only with respect to the iodide/iodine couple but also toward newer high-efficiency redox mediators as well [17-19].

So far, among other conductive polymers, including polyaniline (PANI) and polypyrrole (PPy), PEDOT is the most commonly used CE material. It was reported that PEDOT outperformed both PANI and PPy when used as a counter electrode material [20]. In addition, PANI is not an ideal CE material because it suffers from instability, self-oxidation, and carcinogenic properties [21]. Still, the deposition of PANI tends to give non-uniform films on TCO with insufficient conductivity and low surface area [22]. On the other hand, the main drawback with the PPy counter electrode is its higher charge transfer resistance Rct and the lower conductivity of the films [23]. It can be seen in Figure 1A that over the last five years, the number of publications on "dye-sensitized solar cells" progressively decreased. As expected, this can be ascribed to the increasing interest in the new perovskite solar cells, as depicted by the rise in publications related to this topic. Figure 1B outlines that since 2015 among each component of DSSCs, the topic "counter electrode" covered an almost constant value of about $20 \%$. This suggests that there is still a significant interest in the improvement of this specific component of DSSCs if compared to other subject areas, such as sensitizers, photoanode, or electrolyte [2].

$\mathbf{A}$

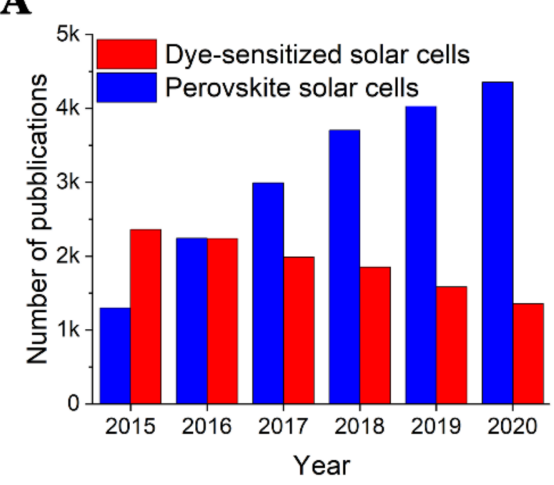

\section{B}

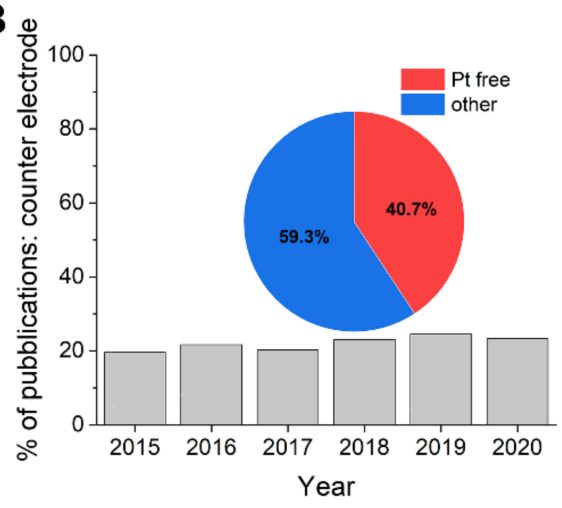

Figure 1. (A) Number of published articles by keyword search: dye-sensitized solar cells" and "perovskite solar cells" from 2015 to 2020. (B) Percentage of publications including the keyword search "counter electrode" in the topic "dye-sensitized solar cell"; inset is the share distribution of publications for counter electrodes from 2015 to 2020. Source: ISI Web of Science, Thomson Reuters.

In this contribution, we review the historical developments and the properties that have made PEDOT-based materials one of the most widely used substrates for DSSC counter electrode fabrication.

\section{Dye-Sensitized Solar Cells: An Overview}

DSSCs are photoelectrochemical solar cells based on the principle of sensitization of wide band-gap mesoporous semiconductors. In a DSSC, the photoanode is typically 
composed of nanometer-sized particles of an n-type mesoporous oxide layer, as represented in Figure 2. The most used material has been anatase $\mathrm{TiO}_{2}$, although other oxides have been explored, including $\mathrm{ZnO}$ and $\mathrm{Nb}_{2} \mathrm{O}_{5}$ [24]. These wide band gap metal oxides are transparent to visible light. Hence, only a modest power conversion can be achieved under solar illumination by exploiting a small portion of the UV wavelengths.

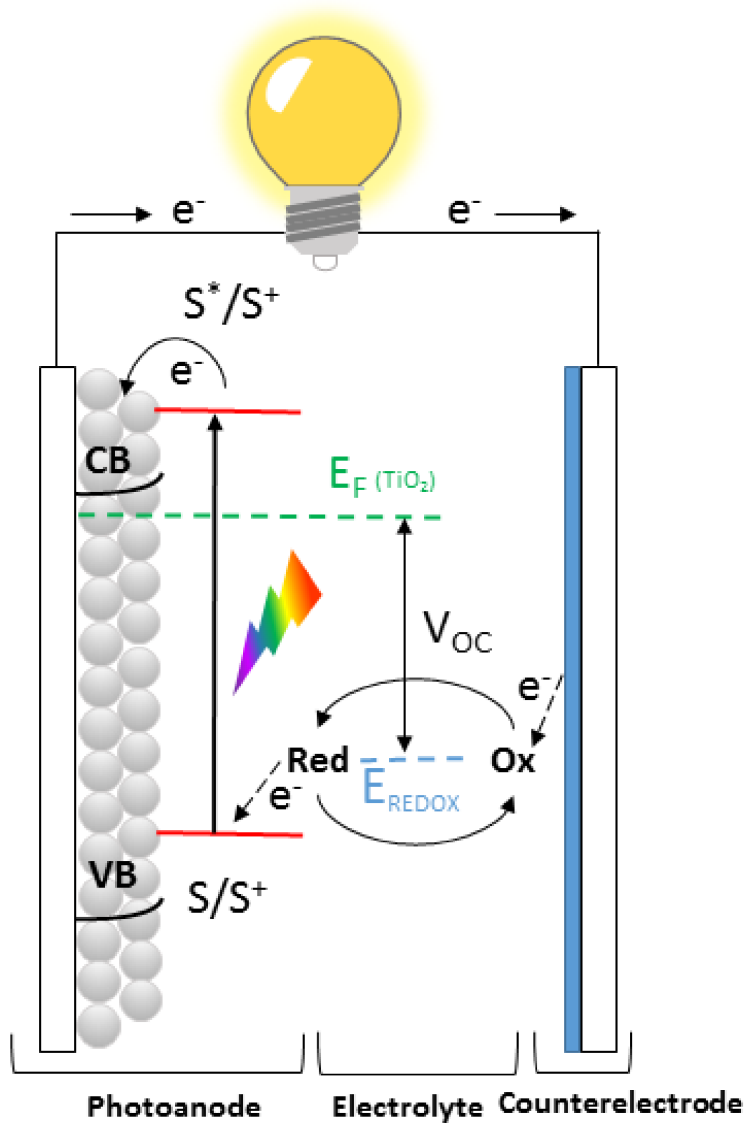

Figure 2. Schematic drawing of DSSCs based on liquid redox mediators. Transparent glass-coated transparent conductive oxides (TCO), such as fluorine doped tin oxide (FTO) or indium tin oxide (ITO), are usually employed to fabricate the charge collecting terminals of the cell, on which $\mathrm{TiO}_{2}$ and the catalytic counter electrode layer are deposited. In solid-state (ss-DSSCs), the liquid electrolyte is replaced by the hole transport material (HTM).

Molecular sensitization was introduced in order to extend the light-harvesting efficiency of these wide gap semiconductors to low-energy photons. A molecular absorber, known as a sensitizer ( $\mathrm{S}$ in Figure 2), is chemically linked to the mesoporous oxide through an anchoring group, typically one or more carboxylic functions. Following light absorption, the dye reaches an electronically excited state $\left(S^{*}\right)$, which undergoes charge injection into the conduction band (CB) of the semiconductor (Equations (1) and (2)) [25].

$$
\begin{gathered}
\text { Photoexcitation } \mathrm{S}+\mathrm{h} v \rightarrow \mathrm{S}^{*} \\
\text { Electron injection } \mathrm{S}^{*}+\mathrm{TiO}_{2} \rightarrow \mathrm{S}++\left(\mathrm{e}-, \mathrm{TiO}_{2}\right)
\end{gathered}
$$

In Figure 3, the chemical structures of some of the most common sensitizers used in DSSCs are reported. Among these structures, we have the most successful isothiocyanate (NCS) substituted ruthenium dyes, such as N3, N719, and Z907, which represent the first generation of highly efficient molecular sensitizers, thanks to broad light absorption populating charge transfer (CT) states undergoing injection on ultrafast time scales [1]. Later entirely organic dyes based on the donor- $\pi$-acceptor architecture were developed, which 
are also endowed with strongly absorbing CT states. Thanks to the electron-withdrawing cyano acrylic linker, dyes, such as D35, Y123, and MK2, achieve high surface coverage and fast injection [26-28].

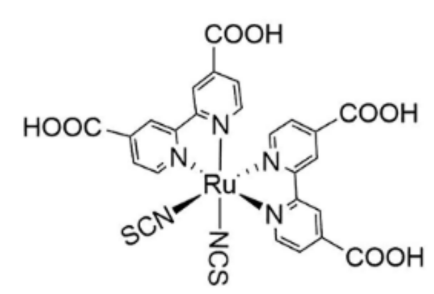

N3

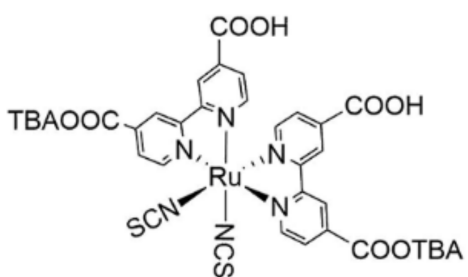

N719

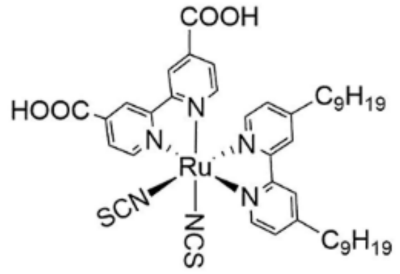

$\mathbf{Z 9 0 7}$

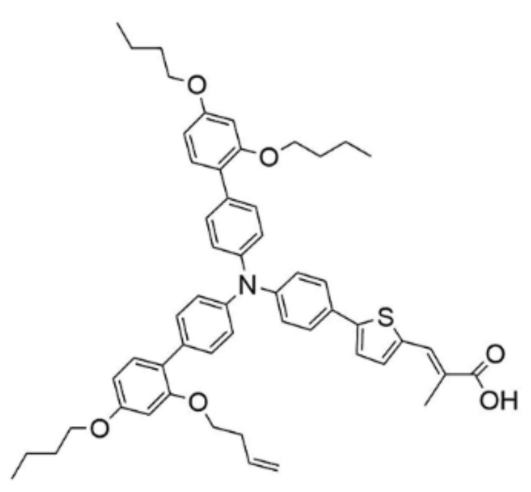

D35

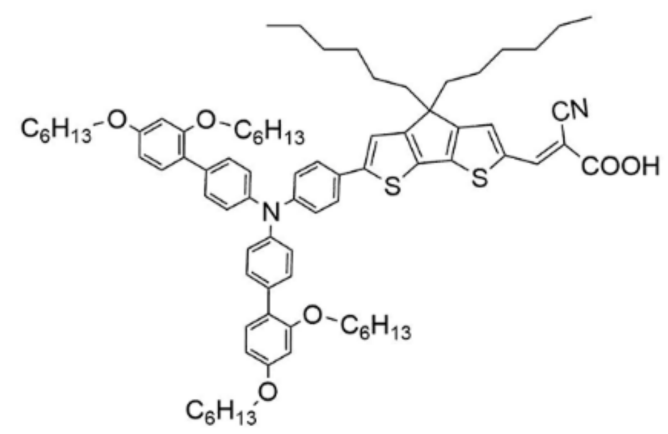

Y123

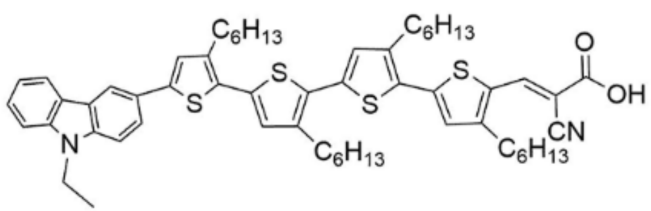

MK2

Figure 3. Some of the most popular inorganic and organic dyes used in DSSCs [1,26-28].

Following charge injection in the semiconductor, the oxidized dye $\mathrm{S}^{+}$is generated, which needs to be reduced before electron recombination occurs. The redox mediator is essential to regenerate the reduced form of the sensitizer $S$, finally closing the entire cycle by collecting the electron at the counter electrode (Equations (3) and (4)).

$$
\text { Dye regeneration: } \mathrm{S}^{+}+(\text {redox shuttle })_{\text {red }} \rightarrow \mathrm{S}+(\text { redox shuttle })_{\mathrm{ox}}
$$

Redox mediator regeneration: (redox shuttle $)_{\mathrm{ox}}+\left(e^{-}, \cdot \mathrm{CE}\right) \rightarrow(\text { redox shuttle })_{\text {red }}$

The photocurrent produced by the DSSC can be expressed as the flux of charge carriers (electrons, having concentration $n$ ) along a given $x$-direction by means of the electrochemical potential gradient generated inside the semiconductor film upon illumination, according to

$$
J=e n u_{n} F+e D_{n} \frac{\partial n}{\partial x}
$$


where $F$ is the electric field possibly present within the semiconductor and $u_{n}$ is the electron mobility, related to the diffusion coefficient $D_{n}$ by

$$
D_{n}=\frac{k T}{e} u_{n}
$$

In the case of mesoporous semiconductors composed of a network of sintered nanocrystals, there is a significant population of localized states (L) in the band gap, which are generally regarded as non-conductive, as opposed to conductive delocalized conduction band $(\mathrm{CB})$ states. Charge transport thus occurs by trapping and detrapping of the carriers from and to conductive states, and, if charge trapping and detrapping are sufficiently fast processes, transport can be described in terms of quasi-equilibrium charge densities in both localized and conductive states [29]. In this latter case, the electron diffusion coefficient $D_{n}$ can be expressed according to 7 [30].

$$
D_{n}=\left(1+\frac{\partial n_{L}}{\partial n_{C B}}\right)^{-1} D_{0}
$$

where $n_{L}$ and $n_{C B}$ indicate the electron density in localized and conductive states, respectively, and $D_{0}$ is the electron diffusion coefficient in the conductive states.

With mesoporous $\mathrm{TiO}_{2}$, charge transport is among the slowest processes occurring in Dye-sensitized solar cells, with a time constant of the order of $1 \mathrm{~ms} \mathrm{[31].} \mathrm{Nevertheless,}$ with suitable redox couples, such as the often-used $\mathrm{I}^{-} / \mathrm{I}_{3}{ }^{-}$couple, regeneration of the dye occurs on a time scale ca. 3 orders of magnitude shorter, preventing to a large extent electron recombination with the oxidized dye. The major charge recombination loss is thus related to the bielectronic reduction of $\mathrm{I}_{3}{ }^{-}$, a slow process (on the tens/hundreds ms time scale) at the photoanode, due to the poor electrocatalytic properties of both $\mathrm{TiO}_{2}$ and FTO. This may result in nearly unit charge collection efficiency by sensitized $\mathrm{TiO}_{2}$ thin films having a typical thickness $\leq 10 \mu \mathrm{m}$. As will be detailed in the following sections, $\mathrm{I}_{3}{ }^{-} / \mathrm{I}^{-}$, the most common redox mediator initially, has been replaced by cobalt and copper redox shuttles which, in some cases, allowed record power conversion to be reached but, being faster monoelectronic couples, also required tuning of the titania film thickness and appropriate surface insulation with respect to electron recapture by the oxidized form of these new redox mediators [32]. From a phenomenological point of view, Dye-sensitized solar cells have been shown to follow the diode equation according to Equation (8).

$$
J=J_{L}-J_{0}\left(\exp \left(-\frac{e V j}{m k T}\right)-1\right)
$$

where $J_{L}$ is the limiting current density depending on the absorbed photon flux, $V j=V+I R$ is the potential drop across the cell, related to the applied bias $V$ in the presence of the potential drop $I R$, where $R$ can be regarded as the total series resistance of the cell and $m$, is the ideality factor of the diode characterized by the equilibrium dark current density $J_{0}$. $m$, Jo, and $\mathrm{R}$ are dependent on the specific chemical nature of the system and summarize the quality of the cell components and interfaces with respect to charge recombination and electron mediator regeneration kinetics [33]. A small dark current (low losses by charge recombination) and a small series resistance (which translates into a small overpotential loss for electrolyte regeneration) generally improve the PCE of the solar cell, given by

$$
\mathrm{PCE}=\left(V_{o c} J_{L} F F\right) / \mathrm{P}_{\mathrm{s}}
$$

where $V_{o c}$ is the open circuit photovoltage $(\mathrm{V}), J_{L}$ is the short circuit photocurrent density $\left(\mathrm{A} \mathrm{m}^{-2}\right), F F$ is the cell fill factor, and $\mathrm{P}_{\mathrm{s}}$ is the total optical power density at the cell surface $\left(\mathrm{W} \mathrm{m}^{-2}\right)$ [1]. The diode (or multi-diode) equation has also been successfully used to model the behavior of organo-lead perovskite solar cells, which, despite their origin in the field of spectral sensitization as a particular example of DSSC, can be really regarded as examples 
of p-i-n junctions, along the lines of other thin-film technologies, where perovskite behave as intrinsic semiconductors capable of transporting both electrons and holes $[34,35]$.

Owing to the fact that DSSCs, like other solar cells, are quantum converters, the efficiency of the photon to electron conversion process is expressed in terms of the ratio between the number of electrons flowing in the external circuit to the number of incident photons. Incident Photon-to-Electron Conversion Efficiency (IPCE) is expressed as the product of three terms related to the key steps of the device operation, as follows:

$$
\operatorname{IPCE}(\lambda)=\operatorname{LHE}(\lambda) \phi_{\text {inj }} \eta_{\mathrm{c}}
$$

where LHE is the light-harvesting efficiency, $\phi_{\text {inj }}$ is the electron injection quantum yield, and $\eta_{\mathrm{c}}$ is the efficiency with which electrons are collected at the photoanode [1].

\section{PEDOT in DSSCs}

\subsection{The Conductive Polymer PEDOT}

PEDOT was synthesized for the first time in 1988 by Jonas and Kirchmeyer by chemical oxidation of EDOT in the presence of polystyrenesulfonic acid [36]. They obtained a water dispersion of PEDOT:PSS paving the way to transform this conductive polymer into one of the most used for different applications. PEDOT can also be prepared by electrochemical synthesis, but in this case, a conductive coating is deposited on the electrode surface [37-39]. The reaction pathway from EDOT to PEDOT consists of initial monoelectronic oxidation of EDOT. Subsequently, a sequence of C-C coupling of two EDOT radical cations, proton losses, and re-aromatization occur until a certain length of newly formed PEDOT oligomers is reached (see Figure 4) [40]. While the exact chain length is not known in detail, some authors reported that in the case of PEDOT:PSS, the molecular weight of the PEDOT oligomers is between 1000 and $2500 \mathrm{Da}$, which is consistent with about 6 to 18 repeating units of EDOT [41]. During the chemical or electrochemical polymerization, neutral oligomers are further oxidized to yield PEDOT in its doped and conductive state. It should be noted that the main charge carriers across PEDOT in its doped state are polarons and bipolarons [40]. In addition, the ratio between EDOT units of PEDOT chains and dopants strongly depends on the ability of the negative charges of the counterions present in the electrolyte to stabilize the positive charge on PEDOT. For monomeric dopants, this parameter is also known as the doping ratio, whereas for polymeric dopants, not all the negative groups are expected to counterbalance the positive charges generated on PEDOT. In the case of chemically prepared PEDOT:PSS (PSS = polystyrene sulfonate), for example, it was reported that only a small fraction of sulfonic acid groups across the PSS chains directly interact with positively charged PEDOT while the other part interacts with water [42]. In general, the real doping ratio can be established through spectroscopic techniques, such as XPS (X-ray photoelectron spectroscopy) or EDS (Energy Dispersive Spectroscopy), but some authors have used electrochemical analysis as well [42-45]. The solubility of PEDOT oligomers is strongly influenced by the synthetic protocol adopted. In particular, if one is interested in obtaining a water dispersion of the conductive polymer, surfactants, such as PSS or Nafion, are preferred [46,47]. Thus, the possibility of obtaining a dispersion/solution of PEDOT:X, where is $X$ represents a general dopant, is limited by the solubility of the conductive polymer, which depends on the nature of the dopant as well as of the solvent. The electrochemical deposition of PEDOT is less restricted in the choice of counter anions since the goal of this process is not a stable dispersion but the precipitation of the PEDOT:X composite on the electrode surface in order to generate a solid conductive polymer thin film. Thus, one can access many options in the composition of the electrolyte, generating materials whose electrochemical response is strongly influenced by the nature of the doping counter anions, as will be shown in the next section [48]. 
$\mathbf{A}$

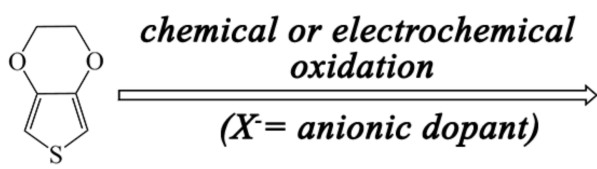

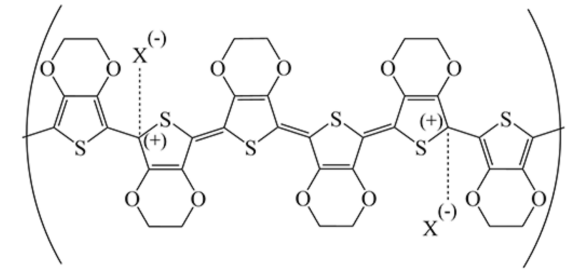

B

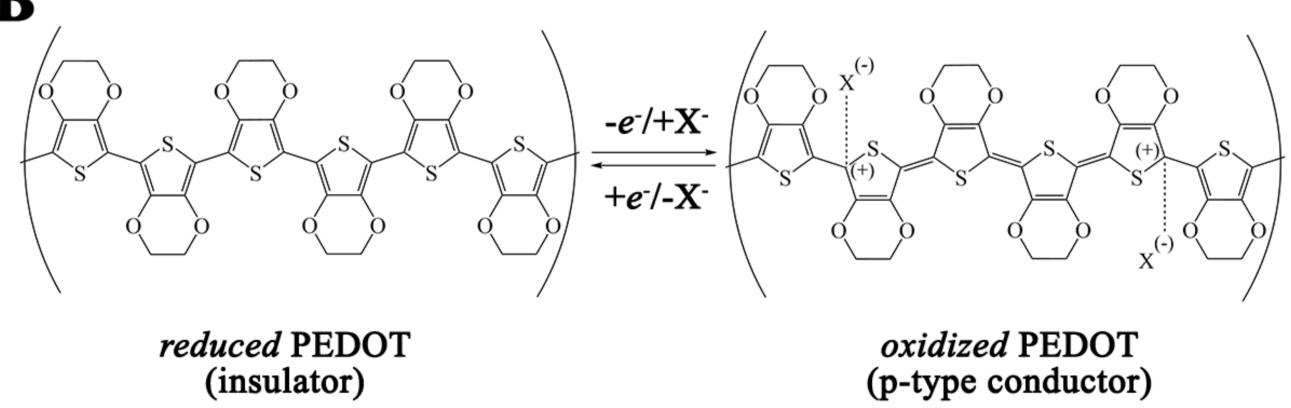

Figure 4. (A) general synthetic route to doped PEDOT:X ( $X$ = generic dopant $)$ and (B) reversible switch between reduced and oxidized forms of PEDOT.

\subsection{PEDOT Based Alternative Counter Electrodes in DSSCs}

\subsubsection{Iodide-Iodine Electrolyte}

Owing to its good conductivity, high flexibility, remarkable stability, and low cost, the use of PEDOT for different applications has significantly increased during the last twenty years. As far as counter electrodes for DSSCs are concerned, high ohmic conductivity is not necessarily a goal that should be reached since PEDOT only forms a thin layer on top of an ohmic electrode (metal or TCO charge collectors). Rather, it is very important that the PEDOT-based material exhibits a good electrocatalytic behavior toward redox mediators used to regenerate the oxidized dye. For example, bare FTO has very high conductivity, but DSSCs which employed this unmodified material as CEs exhibited PCEs of about $0.1 \%$, whereas platinized FTO of PEDOT-based CEs easily exceeded $4 \%$ power conversion [49]. Another important key feature of PEDOT is related to its transparency over the wavelength range of 400-900 nm. The absorption spectrum of oxidized PEDOT is essentially featureless, and a progressive increase in the absorbance is observed only when approaching the NIR region. For these reasons, oxidized PEDOT exhibits a sky blue color. Of course, the transparency of PEDOT CEs decreases as the thickness of the coating increases. In general, a compromise between electrocatalytic properties and film transparency can be obtained, but it should be noted that the absorbance of iodine-based electrolytes is commonly higher than the absorbance of PEDOT CEs in the visible range. Thus, the final color of the device is minimally impacted by the color of PEDOT CE, mostly influenced by the color resulting from the dyed photoanode and the electrolyte. It was also reported that PEDOT films having a thickness on the order of $2 \mu \mathrm{m}$ provided comparable electrocatalytic properties to $50 \mathrm{~nm}$ thick ones, in conjunction with iodine base redox mediator [50]. Thus, a satisfactory electrochemical response can be obtained with PEDOT films having a minimal contribution to the overall light-harvesting of the device.

One of the first reports of PEDOT-based CEs for DSSC was published in 2002 by the group of Prof. Yanagida [51]. They were encouraged by preliminary results by Inganas et al., who outlined that PEDOT can improve the charge transfer between a metal oxide and the iodide/triiodide redox couple, which was, and still is, one of the most popular components in liquid electrolyte DSSCs [37]. About 30-50 nm of PEDOT-TsO (where TsO refers to tosylate group) and PEDOT:PSS were deposited on an ITO surface through chemical oxidation of EDOT or by spin coating a commercial solution, respec- 
tively. The cyclo-voltammetric (CV) response of iodide showed the absence of significant electrocatalytic activity when performed on bare ITO, as shown by the absence of clear oxidation/reduction diffusional waves. On the contrary, good electrocatalytic behavior was observed for PEDOT-TsO, which was comparable to Pt-based electrodes, thereby indicating PEDOT-TsO as a good candidate to substitute Pt in CEs for DSSCs. Interestingly, in the same conditions, electrodes coated with PEDOT:PSS exhibited a poorer electrochemical behavior if compared to PEDOT-TsO. Authors suggested that this could be linked to the exposure of polyanion $\mathrm{PSS}^{-}$, which may sterically and electrostatically block the approach of $\mathrm{I}^{-}$and $\mathrm{I}_{3}{ }^{-}$to the active sites of the PEDOT chain [51]. The results of DSSCs characterization were consistent with the preliminary indications gained by $\mathrm{CV}$ : comparable efficiency parameters $\left(V_{o c}, J_{s c}\right.$ and $\left.F F\right)$ were obtained for PEDOT-TsO and $\mathrm{Pt}$, but cells prepared with PEDOT:PSS based CEs provided the lowest $F F$ values due to the larger series resistance in these cells. The authors also explained this effect is due lower conductivity of PEDOT:PSS films $(10 \mathrm{~S} / \mathrm{cm})$, if compared to PEDOT-TsO of $550 \mathrm{~S} / \mathrm{cm}$. Saito et al. later demonstrated that unlike $\mathrm{Pt}, \mathrm{PEDOT}-\mathrm{TsO}$ exhibited no specific interaction with $\mathrm{I}^{-}$and $\mathrm{I}_{3}{ }^{-}$. They also observed an improved PCE by increasing PEDOT film thickness. This resulted in enhanced electroactive surface area of the CEs, which improved their catalytic response [51]. It is known that the conductivity of chemically prepared PEDOT:PSS can be strongly increased upon treatment with polar solvents, such as DMSO [52,53]. It was found that a modified DMSO-PEDOT:PSS mixed with a small amount of carbon black can outperform conventional $\mathrm{Pt}$ when used as CE in DSSCs. Indeed, cells assembled with a N3 sensitized photoanode, an iodine/iodide-based electrolyte, and the modified PEDOT:PSS CEs yielded a higher cell efficiency of $5.81 \%$ than the equivalent cell assembled with Pt CE $(5.66 \%)$. This result was explained by the combined action of the DMSO treatment, which was beneficial to enhance the conductivity of the PEDOT:PSS film, with the presence of carbon black, which further increases the surface area of the conductive film, yielding a superior catalytic activity [54]. Following a similar procedure, Yue and co-workers prepared PEDOT:PSS/carbon CEs by adding a small amount of graphite to a commercial solution of PEDOT:PSS. They obtained an overall photovoltaic efficiency of $7.6 \%$ by optimizing the annealing temperature of PEDOT:PSS/carbon CEs [55]. Still, the authors of this study claimed that the improved activity of these PEDOT-based composite CEs was mainly due to their larger active surface area compared to the unmodified films, which enhances the electrocatalysis of the $\mathrm{I}^{-} / \mathrm{I}_{3}{ }^{-}$couple, together with their increased conductivity. The use of water dispersible and commercially available PEDOT:PSS can be advantageous if the large scale production of DSSC CEs is undertaken. Indeed, starting from commercial PEDOT suspensions, conductive films could be deposited through scalable wet chemical methods, including spin coating, spray coating, or dip coating. On the other hand, electrodeposition methods are also scalable and enable the use of different doping agents, other than polymeric PSS anions, allowing for the fine tuning of the electrochemical properties of PEDOT films. Interestingly, Xia and co-workers electrodeposited PEDOT in the presence of different counter ions, which besides PSS, included perchlorate $\left(\mathrm{ClO}_{4}{ }^{-}\right)$and tosylate $\left(\mathrm{TsO}^{-}\right)$and observed that all electrodeposited PEDOT CEs gave comparable results to that of Pt (Figure 5) [49].

Indeed, a power conversion efficiency near 7.9\% was reported for all PEDOT counter electrodes with an iodine-based electrolyte which was almost the same as that observed with a platinized counter electrode under otherwise identical conditions.

In a report by Ahmad et al., PEDOT was electrodeposited in the presence of hydrophobic ionic liquids, and it was pointed out that the fine-tuning of the dopant nature and concentration in the polymer matrix is fundamental to improve the electrochemical performance of the resulting polymer. Following this approach, PEDOT-based counter electrodes in contact with an iodide-based electrolyte performed similarly to platinized counter electrodes yielding cells with a power conversion efficiency of 7.93\% [56]. 

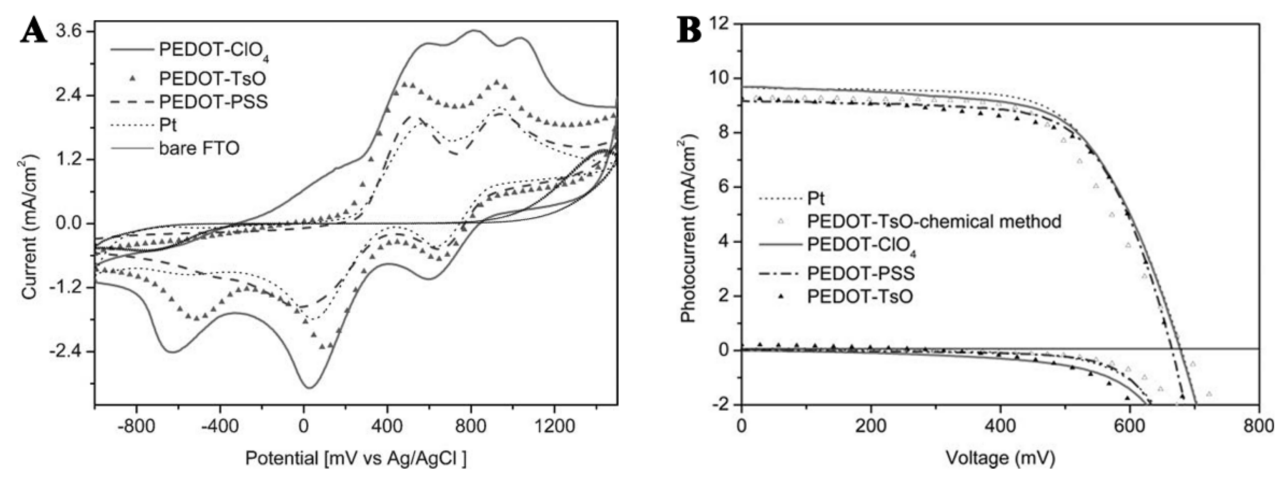

Figure 5. (A) cyclic voltammetry of an iodide/iodine-based electrolyte at different working electrodes, including PEDOT coated FTO, Pt, and bare FTO; (B) Comparison between current density-voltage (JV) curves of the DSSCs solar cells fabricated with different PEDOT counter electrodes and with the reference material Pt. Readapted with permission of Royal Society of Chemistry from reference [49].

Electrodeposition can be used to prepare composite PEDOT materials in which one or more additives can be included within the polymer matrix during the growth of the PEDOT film. For instance, Zhang et al. prepared highly active CEs by electrodepositing PEDOT:TFSI (TFSI $=$ bis(trifluoromethanesulfonyl)imide) in the presence of conductive carbon black [57]. In this way, these authors were able to achieve an overall PCE of $9.8 \%$ in iodide/iodine mediated DSSCs. Interestingly, they also reported a PCE of about $7.6 \%$ when an alternative thiolate-based redox mediator was adopted. The improved electrocatalytic behavior of PEDOT with incorporated conductive carbon black was explained by a lower charge transfer resistance at CE I I electrolyte interface, compared to regular PEDOT [57].

Vapor phase polymerization is another potential technique commonly used to prepare PEDOT-based CEs. Very recently, conversion efficiency of $8.4 \%$ was reported for PEDOT-based DSSCs, in conjunction with an $\mathrm{I}_{3}{ }^{-} / \mathrm{I}^{-}$redox mediator [58]. The authors first deposited a thin layer of $\mathrm{Fe}_{2} \mathrm{O}_{3}$ on FTO, and subsequently, they obtained PEDOT CEs by in situ treatment with EDOT and $\mathrm{HCl}$ : $\mathrm{Fe}^{3+}$, which generated by dissolution of $\mathrm{Fe}_{2} \mathrm{O}_{3}$ upon under acidic conditions, acts as the oxidizing agent of EDOT.

\subsubsection{Alternative Redox Electrolytes}

The $\mathrm{I}_{3}{ }^{-} / \mathrm{I}^{-}$couple generally accounts for fast dye regeneration kinetics coupled to slow recombination with photoinjected electrons, resulting in a long-lived charge separation upon photoexcitation at the sensitized photoanode/electrolyte junction. While this is the main requisite for achieving high power conversion efficiency in the DSSC, $\mathrm{I}^{-} / \mathrm{I}_{3}{ }^{-}$also displays a list of regrettable properties: (1) the triiodide ion absorbs a significant portion of visible light, competing with the dye in light absorption in the blue region of the visible spectrum; (2) $\mathrm{I}^{-} / \mathrm{I}_{3}{ }^{-}$is highly corrosive towards metallic conductors typically used in large area DSSC modules; (3) it is volatile; (4) it limits the open-circuit voltage of the cell due to an unnecessarily low redox potential which brings a large overvoltage loss for dye regeneration. Initial attempts to substitute the $\mathrm{I}_{3}{ }^{-} / \mathrm{I}^{-}$couple with other redox shuttles were reported by the Grätzel group at the EPFL (École polytechnique fédérale de Lausanne). One-electron, outer-sphere redox couples with an oxidation potential more positive than $\mathrm{I}_{3}{ }^{-} / \mathrm{I}^{-}$couple, were first considered. In particular, the behavior of the Co(II)/(III) couple of polypyridine, phenanthroline, and imidazole complexes was evaluated [59]. It appeared that while successful, these monoelectronic redox couples suffered from faster charge recombination than the iodide/iodine couple, which required a careful synthetic design. The Bignozzi's group screened some substituted bipyridine ligands to understand the structure/property relationship of these mediators (some of them are reported in Figure 6), finding the best PCE under one-sun illumination with the sterically hindered $\left[\mathrm{Co}(\mathrm{DTB})_{3}\right]^{2+/ 3+}$ (where DTB is $4,4^{\prime}$-di-tert-butyl-2,2'-dipyridyl) and gold counter electrodes [60]. This was explained by the steric hindrance of tert-butyl groups in DTB, which helped decouple $\mathrm{Co}$ (III) from the photoanode surface, thus reducing the rate of the recombination reaction. The need for 
bulky mediators to counter recombination implied the increase in the hydrodynamic radius of these new shuttles, which impacted negatively on the PCE of the DSSC due to mass transport limitations. Nusbaumer et al. compared the photovoltaic performances of several Co-based DSSCs and found that the $8 \%$ efficiency obtained at $100 \mathrm{~W} / \mathrm{m}^{2}$ was almost halved under full sunlight $\left(1000 \mathrm{~W} / \mathrm{m}^{2}\right)$, and this was mainly ascribed to the diffusional limitation of the photocurrent due to slow mass transport of $\mathrm{Co}(\mathrm{III})$ at the counter electrode [61]. These disadvantages related to the use of coordination compounds as fast single electron shuttles were circumvented in 2010 by the Hagfeldt group, which introduced, for the first time, a combination of a sterically hindered organic triphenylamine-based sensitizer (D35) with selected cobalt polypyridine complex. The organic dye D35 was able to efficiently suppress the recombination thanks to its sterically hindered structure which, in turn, enabled the use of less bulky polypyridine ligands, thereby improving both the electron transfer rate and the mass transport from the resulting cobalt complexes [26]. With overall conversion efficiencies of $6.7 \%$ and open-circuit potentials of more than $0.9 \mathrm{~V}$ under $1000 \mathrm{~W} \mathrm{~m}^{-2}$ AM1.5 G illumination, cobalt mediators were able to beat the iodide/iodine couple under full sun illumination. It was clear that a new generation of devices was now accessible and that to improve the overall efficiency, it is necessary to focus on all aspects of the DSSC. In addition, catalytic materials different than noble metals $(\mathrm{Au}, \mathrm{Pt})$ could be used to fabricate cost-effective high surface area CEs, which could reduce the concentration polarization losses in cobalt mediated DSSCs. Miettunen and co-workers compared the photovoltaic performances of DSSCs assembled with either Pt or chemically oxidized PEDOT CEs and cobalt mediators. In this case, Pt outperformed PEDOT leading to an overall efficiency of about $2 \%$ for the former and $1.3-2 \%$ for the latter [62]. It should be noted that the poor activity of PEDOT:PSS when cast from a chemically prepared dispersion was already observed for iodide-based redox mediators [51]. Nevertheless, it was also reported that Pt, unlike gold, is not the material of choice to account for a fast reduction of Co(III) species, especially when bulky polypyridine ligands are used [63]. Carli et al. published a detailed study that compared the electrocatalytic behavior of different electrochemically prepared PEDOT CEs toward the most relevant cobalt-based redox shuttles of that time [17]. These authors also compared the various PEDOT coated FTO electrodes they fabricated to the Au coated ones since these latter were considered the best substrates to catalyze the $\mathrm{Co}$ (II/III) redox chemistry. PEDOT CEs were prepared by electrochemical deposition in the presence of the anionic dopants perchlorate $\left(\mathrm{ClO}_{4}{ }^{-}\right)$, PSS, and a mixture of perchlorate and sodium dodecyl sulfate (SDS). It was found that PEDOT $/ \mathrm{ClO}_{4}$ was the best electrocatalyst thanks to its highly porous structure, which maximized the contact area with the electrolyte, and brought the smallest diffusional and charge transfer resistances within the explored series. Importantly, PEDOT $/ \mathrm{ClO}_{4}$ outperformed both $\mathrm{Pt}$ and $\mathrm{Au}$ based $\mathrm{CEs}$ as confirmed by the analysis of thin-layer symmetric cells containing $\left[\mathrm{Co}(\text { phen })_{3}\right]^{2+/ 3+}$ or $\left[\mathrm{Co}(\mathrm{bpy})_{3}\right]^{2+/ 3+}$ couples (phen $=1,10$-phenanthroline; bpy $=2,2^{\prime}$-bipyridine). The comparison between the different PEDOT CEs outlined a strong dependence on the chemical structure of the cobalt complexes. In particular, while the less sterically hindered $\left[\mathrm{Co}(\mathrm{bpy})_{3}\right]^{2+/ 3+}$ showed fast kinetic response on all PEDOT based CEs, relatively less facile charge transfer kinetic was observed at the interface between PEDOT:PSS and $\left[\mathrm{Co}(\mathrm{phen})_{3}\right]^{2+/ 3+}$, or, more importantly, with the bulky $\left[\mathrm{Co}(\mathrm{DTB})_{3}\right]^{2+/ 3+}$. Similar results were also observed for PEDOT:SDS CEs, albeit less pronounced if compared to PEDOT:PSS. The authors suggested that sluggish charge transfer kinetics could be due to the hydrophobic nature of $\left[\mathrm{Co}(\mathrm{phen})_{3}\right]^{2+/ 3+}$ and $\left[\mathrm{Co}(\mathrm{DTB})_{3}\right]^{2+/ 3+}$, which resulted in unfavorable interactions with hydrophilic sulfonate or sulfate groups of PSS and SDS, causing a higher activation barrier for the electron transfer to occur, if compared, for example, to PEDOT: $\mathrm{ClO}_{4}$.

Other authors demonstrated that for DSSCs employing the cobalt complexes $\left[\mathrm{Co}(\mathrm{bpy})_{3}\right]^{2+/ 3+}$ and $\left[\mathrm{Co}(\mathrm{phen})_{3}\right]^{2+/ 3+}$, the use of PEDOT-coated CEs can effectively reduce the series resistance of the cell to such an extent to mitigate the mass transport limitation of $\mathrm{Co}(\mathrm{III})$ which often affects these chemical species [64]. 


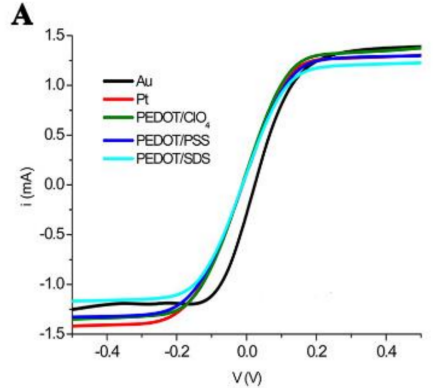

D

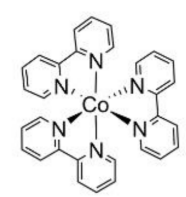

B

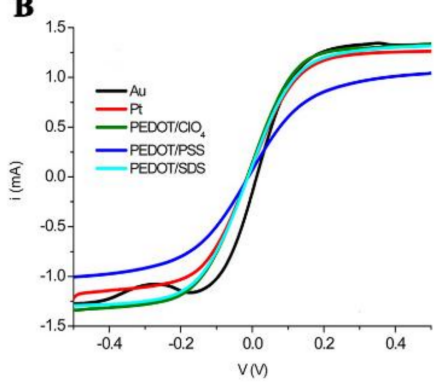

$\mathbf{E}$

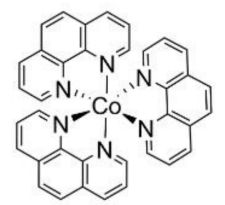

C

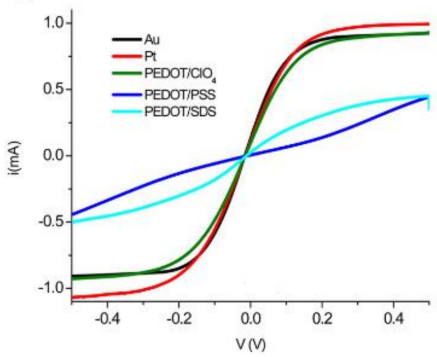

F

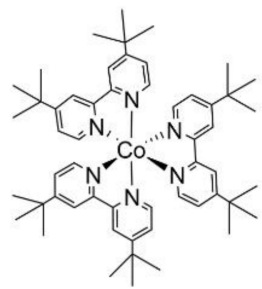

Figure 6. IV curves in symmetric dummy cells containing cobalt-based electron-transfer mediators: $(\mathbf{A}, \mathbf{D})\left[\mathrm{Co}(\mathrm{bpy})_{3}\right]^{3+/ 2+}$, (B,E) $\left[\mathrm{Co}(\text { phen })_{3}\right]^{3+/ 2+},(\mathbf{C}, \mathbf{F})\left[\mathrm{Co}(\mathrm{dtb})_{3}\right]^{3+/ 2+}$. Adapted with permission from Ref [17]. Copyright 2013 American Chemical Society.

Ellis et al. electrodeposited PEDOT:SDS CEs on large area conducting glass and plastic substrates $(9 \mathrm{~cm} \times 9 \mathrm{~cm})$ from a micellar aqueous solution of sodium dodecyl sulfate and EDOT [65]. The electrocatalytic properties of PEDOT:SDS CEs were assessed in DSSCs assembled with the organic dye LEG4 and a $\left[\mathrm{Co}(\mathrm{bpy})_{3}\right]^{2+/ 3+}$ based electrolyte, confirming that PEDOT:SDS counter electrodes exceeded the performance of thermally platinized conducting glass electrodes (Pt-FTO) (see Figure 7). In addition, it was observed that increasing the thickness of PEDOT films is not linked to an improvement in the catalytic performance.

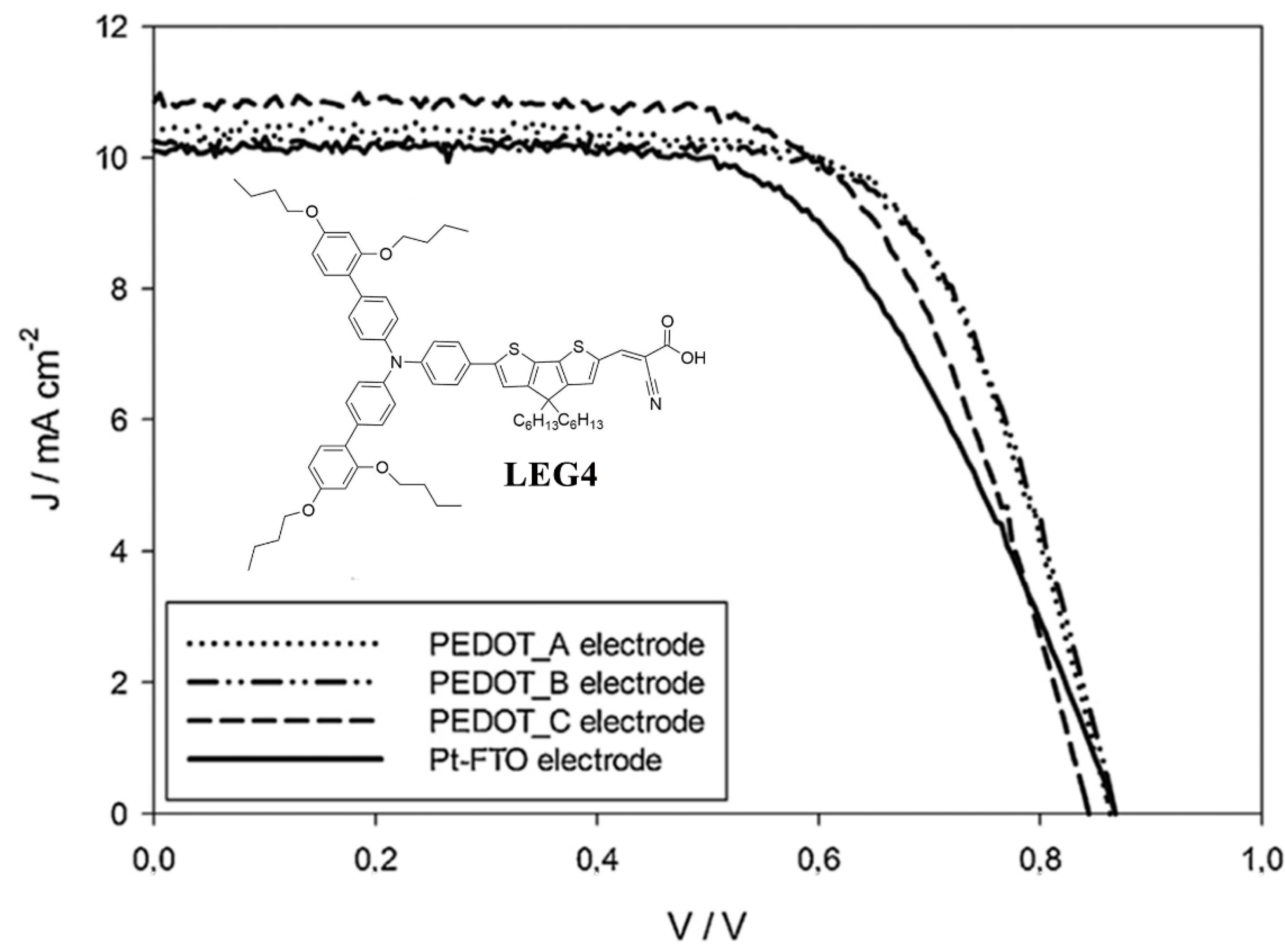

Figure 7. JV curves of cobalt mediated DSSC sensitized by the organic dye LEG4, assembled with different PEDOT counter electrodes (PEDOT:SDS) where the thickness of the polymer films was varied. Adapted from Ref. [65], Copyright (2013), with permission from Elsevier. 
The group of Hagfeldt fabricated PEDOT-TsO CEs through chemical oxidation of EDOT in the presence of iron(III) tris-p-toluenesulfonate, and the resulting films were deposited by spin coating on both FTO and non-conductive glass, respectively. Interestingly, they reported a power conversion efficiency of $6.3 \%$ in the case of DSSCs assembled with cobalt-based redox electrolyte and PEDOT:TsO/glass CEs, very similar to the efficiency of 6.1\% obtained with Pt/FTO CEs [18].

Despite the good results achieved by careful cell and material engineering, the main drawbacks of cobalt redox mediators remained related to their diffusional limitation, together with the high inner-sphere reorganization energy between high spin $\left(\mathrm{Co}^{2+}, \mathrm{d}^{7}\right)$ and low spin $\left(\mathrm{Co}^{3+}, \mathrm{d}^{6}\right)$ states which could slow down the process of dye regeneration [66]. More recent in their application to DSSCs, $\mathrm{Cu}(\mathrm{I} / \mathrm{II})$ couples based on small tetragonally distorted copper complexes showed very good results as alternative redox mediators in DSSCs when used in conjunction with PEDOT based CEs. The typical copper complexes used as an alternative redox mediator in DSSCs, shown in Figure 8, have a smaller size and thus higher diffusion coefficients than the most used Co (II)/(III) octahedral complexes, offering a better mass transport and smaller reorganization energy than the latter and resulting in an efficient regeneration of the oxidized dye [67]. As a result, remarkably high open-circuit voltages above $1 \mathrm{~V}$ under full sun illumination have been reached in DSSCs sensitized by organic dyes [68].

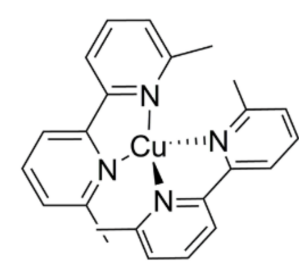

$$
\mathrm{Cu}(\mathrm{dmby})_{2}^{2+/ 1+}
$$

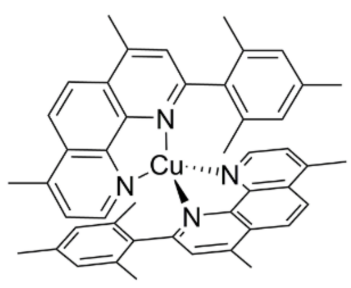

$\mathrm{Cu}(\mathrm{dmmsp})_{2}{ }^{2+/ 1+}$

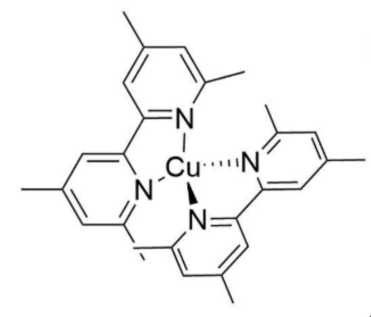

$\mathrm{Cu}(\mathrm{tmbpy})^{2+/ 1+}$

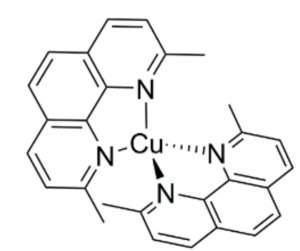

$\mathrm{Cu}(\mathrm{dmp})_{2}{ }^{2+/ 1+}$

Figure 8. Molecular structures of $\mathrm{Cu}$ complexes studied as redox mediators in references [67-69].

Record PCE of $28.9 \%$ under indoor conditions (1000 lux irradiance) and $11.3 \%$ in a standard AM1.5G sunlight were achieved by Freitag et al. using a $\mathrm{Cu}(\mathrm{II} / \mathrm{I})$ redox mediator and electrochemically deposited PEDOT films as counter electrodes [70].

Furthermore, DSSCs fabricated through a new architecture achieved efficiencies of $13.1 \%$. This new approach was aimed at a further reduction in the diffusional path of a $\mathrm{Cu}(\mathrm{II}) / \mathrm{Cu}(\mathrm{I})$ redox mediator, and the cell was fabricated by placing in direct contact the sensitized photoanode with the PEDOT based counter electrode without any spacer [71]. The potential for scale-up of the electrochemical fabrication of the counter electrode was demonstrated by the group of Boschloo. They prepared relatively large area $(5 \mathrm{~cm} \times 5 \mathrm{~cm})$ PEDOT counter electrodes, which were sealed against the counter electrode with epoxy resin and an additional thin layer of $\mathrm{ZrO}_{2}$ to avoid shorting between the electrodes. This architecture, used in conjunction with the $\mathrm{Cu}^{\mathrm{I} / \mathrm{II}}(\mathrm{dmp})_{2}$ redox couple, reproducibly afforded high-performance solar cells with an efficiency of close to $8 \%$ (see Figure 9) [72]. 


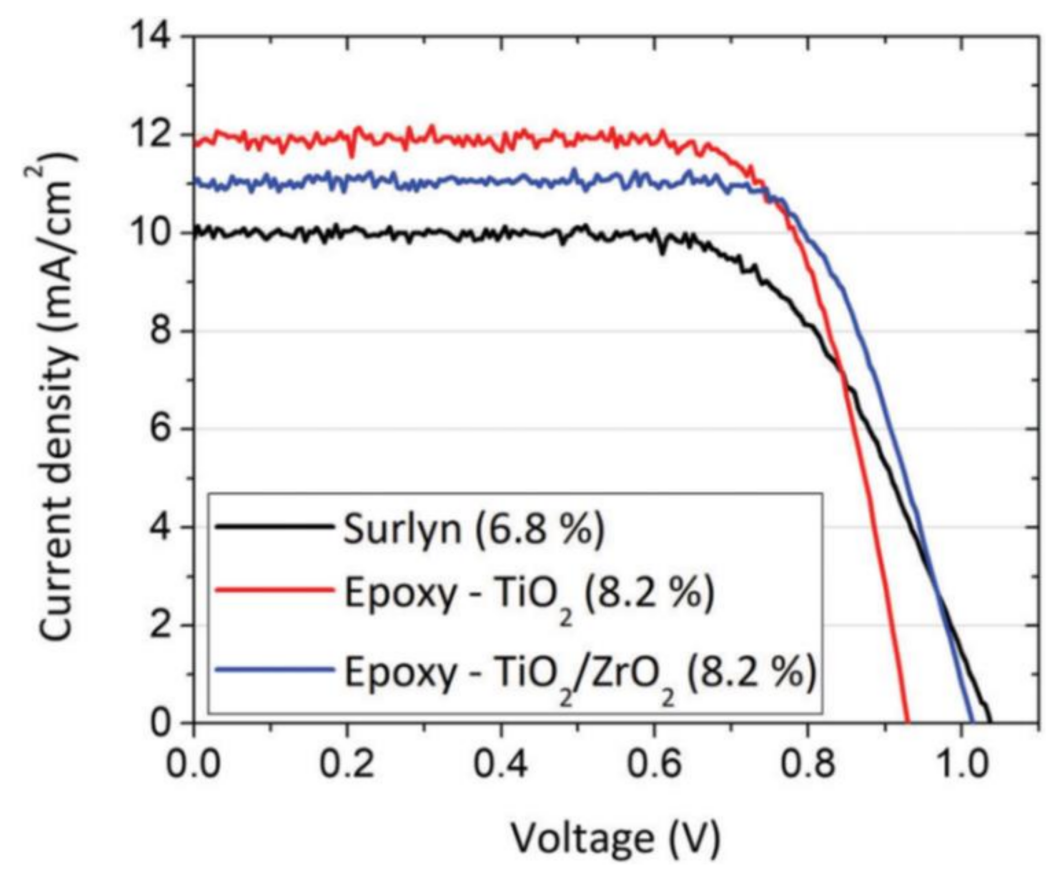

Figure 9. Best JV curves obtained by reducing the inter-electrode distance in the presence of copper redox mediators. Republished with permission of Royal Society of Chemistry, from Ref. [72].

Besides metal-based redox shuttles, another promising family of alternative electron mediators for DSSCs is represented by organic thiolate/disulfide $\left(\mathrm{T}^{-} / \mathrm{T}_{2}\right)$ redox couples (see Figure 10). In 2010, Wang et al. reported the first example of a DSSC employing this new type of redox mediator in conjunction with Z907 dye and Pt CEs [73]. The authors achieved an unprecedented efficiency of $6.4 \%$ with this iodide-free redox electrolyte.<smiles></smiles>

Figure 10. Molecular structures and redox equilibrium in $\mathrm{T}^{-} / \mathrm{T}_{2}$ organic redox shuttle used as an alternative redox mediator by Wang and co-workers [73].

In 2011, the group of Lichen Sun prepared and studied a series of organic thiolate/disulfide redox couples in DSSCs. Additionally, they compared the catalytic activity of the well-known platinized FTO counter electrodes with PEDOT ones. They found that as an alternative CE material, PEDOT exceeded conventional platinized FTO-type of CE for yielding a PCE efficiency of $6.0 \%$ compared to $4.6 \%$ for the latter. Authors outlined that the PEDOT films are much more effective than platinum in reducing the charge-transfer resistance at the electrolyte/PEDOT interface, which, in turn, generates higher fill factor (FF), yielding higher PCE [53].

Later on, Burschka compared the electrocatalytic activity of conventional platinum, cobalt sulfide (CoS), and PEDOT toward organic thiolate/disulfide $\left(\mathrm{T}^{-} / \mathrm{T}_{2}\right)$ redox mediators. Remarkably, an unprecedented power conversion efficiency of $7.9 \%$ under $100 \mathrm{~mW} \mathrm{~cm}^{-2}$ solar irradiation was recorded using a high surface area PEDOT-based counter electrode. In particular, a highly porous structured polymer film with high cat- 
alytic activity and surface area was obtained by electrochemical oxidation of EDOT in the presence of ionic-liquid medium by the potentiostatic mode [74].

In Table 1, the efficiency of PEDOT-based DSSCs fabricated according to different procedures and with various dyes and redox mediators is summarized.

Table 1. Photovoltaic parameters of PEDOT-based DSSCs with various redox mediators and dyes under AM1.5 G illumination.

\begin{tabular}{|c|c|c|c|c|c|}
\hline $\mathrm{CE}$ & Deposition Method & Redox Shuttle & Dye & PCE\% & [Ref.] \\
\hline \multirow{4}{*}{ PEDOT-TsO } & spin coating & $\mathrm{I}_{3}^{-} / \mathrm{I}^{-}$ & N719 & 4.60 & [51] \\
\hline & spin coating & $\mathrm{I}_{3}^{-} / \mathrm{I}^{-}$ & Z907 & 4.1 & [49] \\
\hline & electrochemical & $\mathrm{I}_{3}^{-} / \mathrm{I}^{-}$ & Z907 & 4.0 & [49] \\
\hline & spin coating & {$\left[\mathrm{Co}(\mathrm{bpy})_{3}\right]^{3+/ 2+}$} & LEG4 & 6.3 & [18] \\
\hline \multirow{4}{*}{ PEDOT-PSS } & spin coating & $\mathrm{I}_{3}^{-} / \mathrm{I}^{-}$ & N719 & 2.1 & [51] \\
\hline & electrochemical & $\mathrm{I}_{3}^{-} / \mathrm{I}^{-}$ & Z907 & 4.2 & [49] \\
\hline & dip coating & $\mathrm{I}_{3}^{-} / \mathrm{I}^{-}$ & N3 & 5.8 & [54] \\
\hline & scratch under IR light & $\mathrm{I}_{3}^{-} / \mathrm{I}^{-}$ & N719 & 7.6 & [55] \\
\hline \multirow{4}{*}{$\mathrm{PEDOT}^{-\mathrm{ClO}_{4}}$} & electrochemical & $\mathrm{I}_{3}^{-} / \mathrm{I}^{-}$ & Z907 & 4.2 & [49] \\
\hline & electrochemical & {$\left[\mathrm{Co}(\mathrm{dtb})_{3}\right]^{3+/ 2+}$} & Z907 & 1.49 & [17] \\
\hline & electrochemical & $\mathrm{T}^{-} / \mathrm{T}_{2}$ & ТH305 & 6.0 & [75] \\
\hline & electrochemical & {$\left[\mathrm{Co}(\mathrm{bpy})_{3}\right]^{3+/ 2+}$} & MK2 & 4.2 & [76] \\
\hline \multirow{3}{*}{ PEDOT-TFSI } & electrochemical & $\mathrm{I}_{3}^{-} / \mathrm{I}^{-}$ & N719 & 7.93 & [56] \\
\hline & electrochemical & $\mathrm{I}_{3}^{-} / \mathrm{I}^{-}$ & C106 & 9.8 & [57] \\
\hline & electrochemical & $\mathrm{T}^{-} / \mathrm{T}_{2}$ & C106 & 7.6 & [57] \\
\hline PEDOT-Cl & $\begin{array}{c}\text { vapor } \\
\text { phasepolymerization }\end{array}$ & $\mathrm{I}_{3}^{-} / \mathrm{I}^{-}$ & N719 & 8.42 & [58] \\
\hline \multirow{3}{*}{ PEDOT-FAP } & electrochemical & $\left.[\text { Co(phen })_{3}\right]^{3+/ 2+}$ & Y123 & 9.5 & {$[64]$} \\
\hline & electrochemical & {$\left[\mathrm{Co}(\text { phen })_{3}\right]^{3+/ 2+}$} & Y123 & 10.3 & {$[64]$} \\
\hline & electrochemical & $\mathrm{T}^{-} / \mathrm{T}_{2}$ & Z907 & 7.9 & {$[74]$} \\
\hline \multirow{5}{*}{ PEDOT-SDS } & electrochemical & {$\left[\mathrm{Co}(\mathrm{bpy})_{3}\right]^{3+/ 2+}$} & LEG4 & 6.2 & {$[65]$} \\
\hline & electrochemical & {$\left[\mathrm{Cu}(\mathrm{dmp})_{2}\right]^{1+/ 2+}$} & LEG4 & 8.3 & [68] \\
\hline & electrochemical & {$\left[\mathrm{Cu}(\mathrm{tmby})_{2}\right]^{1+/ 2+}$} & D35/XY1 & 11.3 & {$[70]$} \\
\hline & electrochemical & {$\left[\mathrm{Cu}(\mathrm{tmby})_{2}\right]^{1+/ 2+}$} & $\mathrm{Y} 123 / \mathrm{XY1b}$ & 13.1 & {$[71]$} \\
\hline & electrochemical & {$\left[\mathrm{Cu}(\mathrm{dmp})_{2}\right]^{1+/ 2+}$} & LEG4 & 7.9 & [72] \\
\hline
\end{tabular}

Concerning the stability of PEDOT-based CEs, very recently, Kamppinen et al. reported on the comparative aging tests between electrodeposited PEDOT/SDS and $\mathrm{Pt}$ in conjunction with the $\left[\mathrm{Co}(\mathrm{bpy})_{3}\right]^{2+/ 3+}$ redox electrolyte. DSSC devices assembled with $\mathrm{Pt}$ CEs exhibited higher stability than those fabricated with PEDOT/SDS. Nevertheless, the degradation mechanism in PEDOT-equipped cells is not completely clear. Indeed, while the reduction in the solar cell efficiency is less pronounced in the case of $\mathrm{Pt}$, the counter electrode I electrolyte interfacial charge-transfer resistance was found to be highly stable for PEDOT. This indicates that PEDOT retains its good electrocatalytic behavior but somehow facilitates the degradation of the electrolyte, presumably due to its higher electroactive surface area, which increases the number of redox cycles of the mediator [77]. A recent study confirmed the long-term stability of PEDOT CEs in DSSCs fabricated with an iodinebased electrolyte. A systematic analysis was conducted to compare PEDOT to Pt under light soaking irradiation conditions. Authors demonstrated that DSSC parameters resulted more stable for devices assembled with PEDOT CEs if compared to Pt. This was related to the higher electrochemical stability of PEDOT with respect to $\mathrm{Pt}$ in the presence of iodine electrolyte [78]. This also demonstrated that the ability of PEDOT to form charge-transfer complexes with triiodide ions does not represent a key limitation when this polymer is used as CE in solar cells [79]. High photostability was observed by Grätzel's group for DSSCs constructed with a new organic dye, a copper-based liquid redox mediator, and PEDOT CEs. In particular, PCE retained $92 \%$ of its peak value after $500 \mathrm{~h}$ solar light exposure, 
thereby confirming the high photostability of the entire device, including PEDOT-based CEs [80].

Another important aspect concerning the long-term stability of PEDOT CEs can be related to the possible delamination of the coating that may be exacerbated by the high temperature that a solar cell must face in real outdoor applications. To tackle this issue, our group has investigated the chemical grafting of PEDOT to the surface of FTO glass. This approach consisted of the structural modification of the EDOT monomer by the insertion of a terminal aminopropyl-triethoxysilane (APTES), which was subsequently anchored to the FTO glass. The electrodeposition of PEDOT was performed following standard procedures on EDOT-functionalized-FTOs or un-modified FTO. Sonication and peeling tests confirmed that the new PEDOT-APTES CEs were more stable to delamination if compared to conventional PEDOT CEs. In addition, PEDOT-APTES based CEs displayed enhanced cell efficiencies, decreased charge transfer, and mass transport resistances with respect to both platinum and conventional PEDOT when tested in association to Co(III)/(II) couples [76].

\subsubsection{PEDOT as a Solid State Hole Conductor}

PEDOT has also been successfully used in a variant of DSSCs, known as solidstate DSCs (ss-DSSCs), in which the liquid electrolyte has been replaced by a solid holetransporting material (HTM). In this type of device, the introduction of the HTM may represent a further step towards efficient solar cell operation. Indeed, ss-DSSCs must face some possible issues, such as inadequate nanopore filling, low conductivity, and crystallization of HTM infiltrated in the mesoscopic $\mathrm{TiO}_{2}$ scaffolds, leading to low performances [81]. In general, the HTM is deposited on the top of the sensitized photoanode, and then pore filling is obtained by melting the HTM film above the melting point. This protocol can be adopted especially in the case of low molecular weight HTM or, in general, when the required temperature should not be too high for the dye to decompose. Another common approach consists of casting and evaporation of a liquid solution of the HTM in a volatile solvent. However, the complete filling of the pores of the oxide is not always obtained through these methods. An interesting and more promising alternative is represented by the possibility of in situ electro-polymerization of a layer of HTM. In general, the most followed approach is represented by the in situ photoelectrochemical polymerization (PEP) of PEDOT.

For example, the Hagfeldt group investigated the photoelectrochemical polymer deposition under low light intensity in order to optimize the infiltration of the HTM in the nanoporous $\mathrm{TiO}_{2}$. Indeed, the photoanode coated with the organic dye D35 was immersed into the monomer solution, which consisted of a EDOT derivative (bis-EDOT), to facilitate the introduction of the monomer into the pores of $\mathrm{TiO}_{2}$. Finally, the conductive PEDOT film was obtained by photoelectrochemical oxidation by applying a constant potential on the working electrode under light bias [82]. As summarized in Figure 11, upon photoexcitation of the dye, electrons are injected into the conduction band of $\mathrm{TiO}_{2}$, generating the oxidized dye, which triggers EDOT polymerization. In the working cell, the conduction mechanism occurs through hole injection in PEDOT and transport along the polymer bulk in the form of polarons and bipolarons charge carriers.

In situ photoelectrochemical polymerization of bis-EDOT was also obtained the Z907 $\mathrm{Ru}$ (II) dye, obtaining a ss-DSSC conversion efficiency of $2.6 \%$ with high open-circuit voltage over $0.8 \mathrm{~V}$ [83]. Yanagida et al. investigated the role of the doping anions $\mathrm{ClO} 4-, \mathrm{CF} 3 \mathrm{SO} 3-$, BF4-, and TFSI- on PEDOT as a hole conductor in ss-DSSCs. They found that a careful selection of different counterions can lead to an effective way to modulate the conductivity of PEDOT when used as HTM in solid-state devices. In addition, these doping anions are directly linked to the conversion efficiency of ss-DSSCs and, in particular, it was observed that the dopant $\mathrm{TFSI}^{-}$is the most effective in reducing the series and shunt resistance of the cell, thereby representing a promising approach to the scalable preparation of solid-state transparent photoelectrochemical devices [84]. Following a slightly different approach, 
long-term stable and highly efficient ss-DSSC was achieved very recently through the enhanced interfacial contact properties of PEDOT as HTM in conjunction with the wellknown amphiphilic ruthenium sensitizer Z907. In this study, the PEDOT-based HTM layer was prepared by thermal polymerization of a monomer derivative that was previously infiltrated through the nanoporous metal oxide. The authors compared the stability of a typical liquid DSSC with the new ss-DSSC and were able to confirm the stable response resulted from the intimate contact between the dye sensitizer and the PEDOT HTM, which ensured efficient regeneration of the former [85].

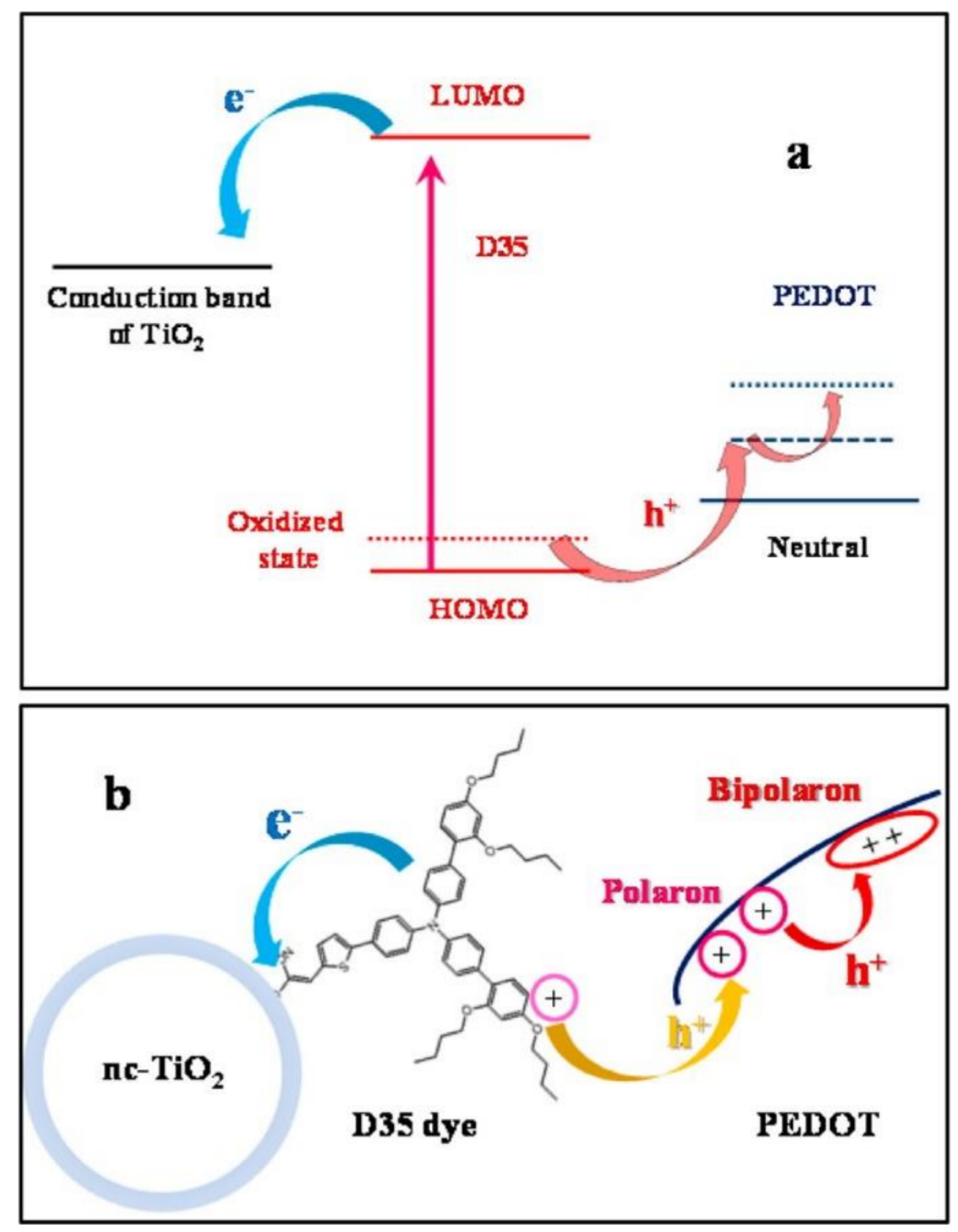

Figure 11. Use of PEDOT as hole transporting layer in ss-DSSCs: (a) energy level diagrams and (b) charge separation pathways relevant to ss-DSSC functioning. Reprinted with permission from [82]. Copyright 2013 American Chemical Society.

\section{Conclusions and Outlook}

Since 1991 DSSCs have emerged as efficient alternative devices for converting solar energy into electrical energy mainly thanks to their low cost, easy preparation, high efficiency, and environmental benignity. Over the last three decades, research has been oriented towards the optimization of photoanodes, electrolytes, and counter electrodes, leading to certified efficiencies of $13.0 \%$ in liquid electrolyte-based devices. The counter electrode is of fundamental importance since it significantly influences both the performance and cost of DSSCs. Among conductive polymers to fabricate Pt-free CEs, PEDOT exhibited the best performance. 
This review outlines the use of PEDOT films as catalytic counter electrodes for DSSCs. While useful as an alternative substrate to noble metal electrodes when using iodide/iodine electrolytes, PEDOT electrodes really played a major role in the development of cells based on alternative redox mediators, notably copper- and cobalt-based electrolytes, which were instrumental in achieving record solar to electrical power conversion efficiencies. Given that the counter electrode plays a crucial role in building high performing as well as stable DSSCs, PEDOT is contributing to the practical implementation of transparent solar cells for building integration. In particular, energy conversion under indoor conditions is becoming one of the most appealing applications of DSSCs, where, under low intensity and diffuse illumination, they represent one of the most promising possibilities for clever energy conversion and reutilization. Future development should focus on the stability of the interface between PEDOT and the electrolyte, and on its role on the overall device stability, for which at the time of the writing of this manuscript, mostly preliminary but promising data are available.

Author Contributions: Conceptualization, S.C. (Stefano Carli), E.M., S.C. (Stefano Caramori); writingoriginal draft preparation, S.C. (Stefano Carli); writing-review and editing, S.C. (Stefano Caramori) and C.A.B. All authors have read and agreed to the published version of the manuscript.

Funding: E.M. and S.C. (Stefano Caramori) are grateful to Emilia Romagna Region (Fondo Sociale Europeo, Programma Operativo 2014-2020) for a research grant.

Institutional Review Board Statement: Not applicable.

Informed Consent Statement: Not applicable.

Data Availability Statement: No datasets were generated or analyzed during the current study.

Conflicts of Interest: The authors declare no conflict of interest.

\section{References}

1. Hagfeldt, A.; Boschloo, G.; Sun, L.; Kloo, L.; Pettersson, H. Dye-Sensitized Solar Cells. Chem. Rev. 2010, 110, 6595-6663. [CrossRef] [PubMed]

2. Ye, M.; Wen, X.; Wang, M.; Iocozzia, J.; Zhang, N.; Lin, C.; Lin, Z. Recent advances in dye-sensitized solar cells: From photoanodes, sensitizers and electrolytes to counter electrodes. Mater. Today 2015, 18, 155-162. [CrossRef]

3. Wu, J.; Lan, Z.; Lin, J.; Huang, M.; Huang, Y.; Fan, L.; Luo, G. Counter electrodes in dye-sensitized solar cells. Chem. Soc. Rev. 2017, 46, 5975-6023. [CrossRef] [PubMed]

4. Smestad, G.; Bignozzi, C.; Argazzi, R. Testing of dye sensitized TiO2 solar cells I: Experimental photocurrent output and conversion efficiencies. Sol. Energy Mater. Sol. Cells 1994, 33, 253. [CrossRef]

5. Bay, L.; West, K.; Winther-Jensen, B.; Jacobsen, T. Electrochemical reaction rates in a dye-sensitised solar cell-The iodide/triiodide redox system. Sol. Energy Mater. Sol. Cells 2006, 90, 341-351. [CrossRef]

6. Ciceroni, C.; Agresti, A.; Di Carlo, A.; Brunetti, F. Graphene Oxide for DSSC, OPV and Perovskite Stability; Elsevier Inc.: Amsterdam, The Netherlands, 2018; ISBN 9780128111659.

7. Li, G.; Zhu, R.; Yang, Y. Polymer solar cells. Nat. Photonics 2012, 6, 153-161. [CrossRef]

8. Ameri, T.; Khoram, P.; Min, J.; Brabec, C.J. Organic ternary solar cells: A review. Adv. Mater. 2013, 25, 4245-4266. [CrossRef]

9. NREL Best Research-Cell Efficiency Chart. Available online: https://www.nrel.gov/pv/assets/pdfs/best-research-cellefficiencies.20190802.pdf (accessed on 10 April 2021).

10. De Bastiani, M.; Dell'Erba, G.; Gandini, M.; D’Innocenzo, V.; Neutzner, S.; Kandada, A.R.S.; Grancini, G.; Binda, M.; Prato, M.; Ball, J.M.; et al. Ion migration and the role of preconditioning cycles in the stabilization of the J-V characteristics of inverted hybrid perovskite solar cells. Adv. Energy Mater. 2016, 6, 1-9. [CrossRef]

11. Bryant, D.; Aristidou, N.; Pont, S.; Sanchez-Molina, I.; Chotchunangatchaval, T.; Wheeler, S.; Durrant, J.R.; Haque, S.A. Light and oxygen induced degradation limits the operational stability of methylammonium lead triiodide perovskite solar cells. Energy Environ. Sci. 2016, 9, 1655-1660. [CrossRef]

12. Conings, B.; Drijkoningen, J.; Gauquelin, N.; Babayigit, A.; D’Haen, J.; D’Olieslaeger, L.; Ethirajan, A.; Verbeeck, J.; Manca, J.; Mosconi, E.; et al. Intrinsic Thermal Instability of Methylammonium Lead Trihalide Perovskite. Adv. Energy Mater. 2015, 5, 1-8. [CrossRef]

13. Olsen, E.; Hagen, G.; Eric Lindquist, S. Dissolution of platinum in methoxy propionitrile containing LiI/I2. Sol. Energy Mater. Sol. Cells 2000, 63, 267-273. [CrossRef]

14. Thomas, J.P.; Zhao, L.; McGillivray, D.; Leung, K.T. High-efficiency hybrid solar cells by nanostructural modification in PEDOT:PSS with co-solvent addition. J. Mater. Chem. A 2014, 2, 2383-2389. [CrossRef] 
15. Yu, J.C.; Hong, J.A.; Jung, E.D.; Kim, D.B.; Baek, S.M.; Lee, S.; Cho, S.; Park, S.S.; Choi, K.J.; Song, M.H. Highly efficient and stable inverted perovskite solar cell employing PEDOT:GO composite layer as a hole transport layer. Sci. Rep. 2018, 8, 3-11. [CrossRef] [PubMed]

16. Liu, J.; Pathak, S.; Stergiopoulos, T.; Leijtens, T.; Wojciechowski, K.; Schumann, S.; Kausch-Busies, N.; Snaith, H.J. Employing PEDOT as the p-type charge collection layer in regular organic-inorganic perovskite solar cells. J. Phys. Chem. Lett. 2015, 6, 1666-1673. [CrossRef]

17. Carli, S.; Busatto, E.; Caramori, S.; Boaretto, R.; Argazzi, R.; Timpson, C.J.; Bignozzi, C.A. Comparative evaluation of catalytic counter electrodes for Co(III)/(II) electron shuttles in regenerative photoelectrochemical cells. J. Phys. Chem. C 2013, 117, 5142-5153. [CrossRef]

18. Park, B.W.; Pazoki, M.; Aitola, K.; Jeong, S.; Johansson, E.M.J.; Hagfeldt, A.; Boschloo, G. Understanding interfacial charge transfer between metallic PEDOT counter electrodes and a cobalt redox shuttle in dye-sensitized solar cells. ACS Appl. Mater. Interfaces 2014, 6, 2074-2079. [CrossRef]

19. Kavan, L.; Saygili, Y.; Freitag, M.; Zakeeruddin, S.M.; Hagfeldt, A.; Grätzel, M. Electrochemical Properties of Cu(II/I)-Based Redox Mediators for Dye-Sensitized Solar Cells. Electrochim. Acta 2017, 227, 194-202. [CrossRef]

20. Stojanović, M.; Flores-Diaz, N.; Ren, Y.; Vlachopoulos, N.; Pfeifer, L.; Shen, Z.; Liu, Y.; Zakeeruddin, S.M.; Milić, J.V.; Hagfeldt, A. The Rise of Dye-Sensitized Solar Cells: From Molecular Photovoltaics to Emerging Solid-State Photovoltaic Technologies. Helv. Chim. Acta 2021, 104, e2000230. [CrossRef]

21. Yun, S.; Hagfeldt, A.; Ma, T. Pt-free counter electrode for dye-sensitized solar cells with high efficiency. Adv. Mater. 2014, 26, 6210-6237. [CrossRef]

22. Gunasekera, S.S.B.; Perera, I.R.; Gunathilaka, S.S. Conducting Polymers as Cost Effective Counter Electrode Material in DyeSensitized Solar Cells. In Solar Energy. Energy, Environment, and Sustainability; Tyagi, H., Chakraborty, P., Powar, S., Agarwal, A., Eds.; Springer: Singapore, 2020; pp. 345-371, ISBN 9789811506758.

23. Saranya, K.; Rameez, M.; Subramania, A. Developments in conducting polymer based counter electrodes for dye-sensitized solar cells-An overview. Eur. Polym. J. 2015, 66, 207-227. [CrossRef]

24. Tennakone, K.; Kumara, G.R.R.A.; Kottegoda, I.R.M.; Perera, V.P.S. An efficient dye-sensitized photoelectrochemical solar cell made from oxides of tin and zinc. Chem. Commun. 1999, 8, 15-16. [CrossRef]

25. Graetzel, M. Solar Energy Conversion by Dye-Sensitized Photovoltaic Cells. Inorg. Chem. 2005, 44, 6841-6851. [CrossRef]

26. Feldt, S.M.; Gibson, E.A.; Gabrielsson, E.; Sun, L.; Boschloo, G.; Hagfeldt, A. Design of organic dyes and cobalt polypyridine redox mediators for high-efficiency dye-sensitized solar cells. J. Am. Chem. Soc. 2010, 132, 16714-16724. [CrossRef]

27. Kashif, M.K.; Axelson, J.C.; Duffy, N.W.; Forsyth, C.M.; Chang, C.J.; Long, J.R.; Spiccia, L.; Bach, U. A new direction in dyesensitized solar cells redox mediator development: In situ fine-tuning of the cobalt(II)/(III) redox potential through lewis base interactions. J. Am. Chem. Soc. 2012, 134, 16646-16653. [CrossRef] [PubMed]

28. Tsao, H.N.; Yi, C.; Moehl, T.; Yum, J.H.; Zakeeruddin, S.M.; Nazeeruddin, M.K.; Grätzel, M. Cyclopentadithiophene bridged donor-acceptor dyes achieve high power conversion efficiencies in dye-sensitized solar cells based on the tris-cobalt bipyridine redox couple. ChemSusChem 2011, 4, 591-594. [CrossRef] [PubMed]

29. Bisquert, J.; Vikhrenko, V.S. Interpretation of the time constants measured by kinetic techniques in nanostructured semiconductor electrodes and dye-sensitized solar cells. J. Phys. Chem. B 2004, 108, 2313-2322. [CrossRef]

30. Bisquert, J.; Fabregat-Santiago, F. Impedance Spectroscopy: A General Introduction and Application To Dye-Sensitized Solar Cells. In Dye-Sensitized Solar Cells; Kalyanasundaram, K., Ed.; CRC Press: Boca Raton, FL, USA, 2010.

31. Peter, L.M.; Duffy, N.W.; Wang, R.L.; Wijayantha, K.G.U. Transport and interfacial transfer of electrons in dye-sensitized nanocrystalline solar cells. J. Electroanal. Chem. 2002, 524-525, 127-136. [CrossRef]

32. Iftikhar, H.; Sonai, G.G.; Hashmi, S.G.; Nogueira, A.F.; Lund, P.D. Progress on electrolytes development in dye-sensitized solar cells. Materials 2019, 12, 1998. [CrossRef] [PubMed]

33. Green, A.N.M.; Palomares, E.; Haque, S.A.; Kroon, J.M.; Durrant, J.R. Charge transport versus recombination in dye-sensitized solar cells employing nanocrystalline $\mathrm{TiO}_{2}$ and $\mathrm{SnO}_{2}$ films. J. Phys. Chem. B 2005, 109, 12525-12533. [CrossRef] [PubMed]

34. Miyano, K.; Tripathi, N.; Yanagida, M.; Shirai, Y. Lead Halide Perovskite Photovoltaic as a Model p-i-n Diode. Acc. Chem. Res. 2016, 49, 303-310. [CrossRef]

35. Ball, J.M.; Lee, M.M.; Hey, A.; Snaith, H.J. Low-temperature processed meso-superstructured to thin-film perovskite solar cells. Energy Environ. Sci. 2013, 6, 1739-1743. [CrossRef]

36. Friedrich, J.; Kirchmeyer, S.; Gerhard, H.; Werner, S.; Jurgen, H.; Michael, D. Polythiophenes, Process for Their Preparation and Their Use. Patent US4987042A, 22 April 1988.

37. Yohannes, T.; Inganäs, O. Photoelectrochemical studies of the junction between poly[3-(4-octylphenyl)thiophene] and a redox polymer electrolyte. Sol. Energy Mater. Sol. Cells 1998, 51, 193-202. [CrossRef]

38. Sotzing, G.A.; Reynolds, J.R.; Steel, P.J. Poly(3,4-ethylenedioxythiophene) (PEDOT) prepared via electrochemical polymerization of EDOT, 2,2'-Bis(3,4-ethylenedioxythiophene) (BiEDOT), and their TMS derivatives. Adv. Mater. 1997, 9, 795-798. [CrossRef]

39. Elschner, A.; Kirchmeyer, S.; Lövenich, W.; Merker, U.; Reuter, K. PEDOT: Principles and Applications of an Intrinsically Conductive Polyme; CRC Press: Boca Raton, FL, USA, 2010; ISBN 9781420069129.

40. Zozoulenko, I.; Singh, A.; Singh, S.K.; Gueskine, V.; Crispin, X.; Berggren, M. Polarons, Bipolarons, And Absorption Spectroscopy of PEDOT. ACS Appl. Polym. Mater. 2019, 1, 83-94. [CrossRef] 
41. Kirchmeyer, S.; Reuter, K. Scientific importance, properties and growing applications of poly(3,4-ethylenedioxythiophene). J. Mater. Chem. 2005, 15, 2077-2088. [CrossRef]

42. Zotti, G.; Zecchin, S.; Schiavon, G.; Louwet, F.; Groenendaal, L.; Crispin, X.; Osikowicz, W.; Salaneck, W.; Fahlman, M. Electrochemical and XPS studies toward the role of monomeric and polymeric sulfonate counterions in the synthesis, composition, and properties of poly(3,4-ethylenedioxythiophene). Macromolecules 2003, 36, 3337-3344. [CrossRef]

43. Greczynski, G.; Kugler, T.; Salaneck, W.R. Characterization of the PEDOT-PSS system by means of X-ray and ultraviolet photoelectron spectroscopy. Thin Solid Films 1999, 354, 129-135. [CrossRef]

44. Tang, H.; Zhu, L.; Harima, Y.; Yamashita, K. Chronocoulometric determination of doping levels of polythiophenes: Influences of overoxidation and capacitive processes. Synth. Met. 2000, 110, 105-113. [CrossRef]

45. Li, G.; Pickup, P.G. Ion transport in poly(3,4-ethylenedioxythiophene)-poly(styrene-4- sulfonate) composites. Phys. Chem. Chem. Phys. 2000, 2, 1255-1260. [CrossRef]

46. Groenendaal, B.L.; Jonas, F.; Freitag, D.; Pielartzik, H.; Reynolds, J.R. Poly(3,4-ethylenedioxythiophene) and Its Derivatives: Past, Present, and Future. Adv. Mater. 2000, 12, 481-494. [CrossRef]

47. Carli, S.; Di Lauro, M.; Bianchi, M.; Murgia, M.; De Salvo, A.; Prato, M.; Fadiga, L.; Biscarini, F. Water-Based PEDOT:Nafion Dispersion for Organic Bioelectronics. ACS Appl. Mater. Interfaces 2020, 12, 29807-29817. [CrossRef]

48. Gueye, M.N.; Carella, A.; Faure-Vincent, J.; Demadrille, R.; Simonato, J.-P. Progress in understanding structure and transport properties of PEDOT-based materials: A critical review. Prog. Mater. Sci. 2020, 108, 100616. [CrossRef]

49. Xia, J.; Masaki, N.; Jiang, K.; Yanagida, S. The influence of doping ions on poly(3,4-ethylenedioxythiophene) as a counter electrode of a dye-sensitized solar cell. J. Mater. Chem. 2007, 17, 2845-2850. [CrossRef]

50. Saito, Y.; Kubo, W.; Kitamura, T.; Wada, Y.; Yanagida, S. I-/I3- redox reaction behavior on poly (3,4-ethylenedioxythiophene) counter electrode in dye-sensitized solar cells. J. Photochem. Photobiol. A Chem. 2004, 164, 153-157. [CrossRef]

51. Saito, Y.; Kitamura, T.; Wada, Y.; Yanagida, S. Application of poly(3,4-ethylenedioxythiophene) to counter electrode in dyesensitized solar cells. Chem. Lett. 2002, 31, 1060-1061. [CrossRef]

52. Ouyang, J.; Xu, Q.; Chu, C.W.; Yang, Y.; Li, G.; Shinar, J. On the mechanism of conductivity enhancement in poly(3,4- ethylenedioxythiophene):poly(styrene sulfonate) film through solvent treatment. Polymer 2004, 45, 8443-8450. [CrossRef]

53. Shi, H.; Liu, C.; Jiang, Q.; Xu, J. Effective Approaches to Improve the Electrical Conductivity of PEDOT:PSS: A Review. Adv. Electron. Mater. 2015, 1, 1-16. [CrossRef]

54. Chen, J.G.; Wei, H.Y.; Ho, K.C. Using modified poly(3,4-ethylene dioxythiophene): Poly(styrene sulfonate) film as a counter electrode in dye-sensitized solar cells. Sol. Energy Mater. Sol. Cells 2007, 91, 1472-1477. [CrossRef]

55. Yue, G.T.; Wu, J.H.; Xiao, Y.M.; Lin, J.M.; Huang, M.L.; Fan, L.Q.; Yao, Y. A dye-sensitized solar cell based on PEDOT: PSS counter electrode. Chin. Sci. Bull. 2013, 58, 559-566. [CrossRef]

56. Ahmad, S.; Yum, J.H.; Zhang, X.; Grätzel, M.; Butt, H.J.; Nazeeruddin, M.K. Dye-sensitized solar cells based on poly (3,4ethylenedioxythiophene) counter electrode derived from ionic liquids. J. Mater. Chem. 2010, 20, 1654-1658. [CrossRef]

57. Zhang, J.; Long, H.; Miralles, S.G.; Bisquert, J.; Fabregat-Santiago, F.; Zhang, M. The combination of a polymer-carbon composite electrode with a high-absorptivity ruthenium dye achieves an efficient dye-sensitized solar cell based on a thiolate-disulfide redox couple. Phys. Chem. Chem. Phys. 2012, 14, 7131-7136. [CrossRef]

58. Kouhnavard, M.; Yifan, D.; D'Arcy, J.M.; Mishra, R.; Biswas, P. Highly conductive PEDOT films with enhanced catalytic activity for dye-sensitized solar cells. Sol. Energy 2020, 211, 258-264. [CrossRef]

59. Nusbaumer, H.; Moser, J.E.; Zakeeruddin, S.M.; Nazeeruddin, M.K.; Grätzel, M. CoII(dbbip)22+ complex rivals tri-iodide/iodide redox mediator in dye-sensitized photovoltaic cells. J. Phys. Chem. B 2001, 105, 10461-10464. [CrossRef]

60. Cazzanti, S.; Caramori, S.; Argazzi, R.; Elliott, C.M.; Bignozzi, C.A. Efficient non-corrosive electron-transfer mediator mixtures for dye-sensitized solar cells. J. Am. Chem. Soc. 2006, 128, 9996-9997. [CrossRef]

61. Nusbaumer, H.; Zakeeruddin, S.M.; Moser, J.E.; Grätzel, M. An alternative efficient redox couple for the dye-sensitized solar cell system. Chem. A Eur. J. 2003, 9, 3756-3763. [CrossRef]

62. Miettunen, K.; Saukkonen, T.; Li, X.; Law, C.; Sheng, Y.K.; Halme, J.; Tiihonen, A.; Barnes, P.R.F.; Ghaddar, T.; Asghar, I.; et al. Do Counter Electrodes on Metal Substrates Work with Cobalt Complex Based Electrolyte in Dye Sensitized Solar Cells? J. Electrochem. Soc. 2013, 160, H132-H137. [CrossRef]

63. Sapp, S.A.; Elliott, C.M.; Contado, C.; Caramori, S.; Bignozzi, C.A. Substituted polypyridine complexes of cobalt(II/III) as efficient electron-transfer mediators in dye-sensitized solar cells. J. Am. Chem. Soc. 2002, 124, 11215-11222. [CrossRef]

64. Tsao, H.N.; Burschka, J.; Yi, C.; Kessler, F.; Nazeeruddin, M.K.; Grätzel, M. Influence of the interfacial charge-transfer resistance at the counter electrode in dye-sensitized solar cells employing cobalt redox shuttles. Energy Environ. Sci. 2011, 4, 4921-4924. [CrossRef]

65. Ellis, H.; Vlachopoulos, N.; Häggman, L.; Perruchot, C.; Jouini, M.; Boschloo, G.; Hagfeldt, A. PEDOT counter electrodes for dye-sensitized solar cells prepared by aqueous micellar electrodeposition. Electrochim. Acta 2013, 107, 45-51. [CrossRef]

66. Mosconi, E.; Yum, J.H.; Kessler, F.; Gómez García, C.J.; Zuccaccia, C.; Cinti, A.; Nazeeruddin, M.K.; Grätzel, M.; De Angelis, F. Cobalt electrolyte/dye interactions in dye-sensitized solar cells: A combined computational and experimental study. J. Am. Chem. Soc. 2012, 134, 19438-19453. [CrossRef] 
67. Saygili, Y.; Söderberg, M.; Pellet, N.; Giordano, F.; Cao, Y.; Munoz-García, A.B.; Zakeeruddin, S.M.; Vlachopoulos, N.; Pavone, M.; Boschloo, G.; et al. Copper Bipyridyl Redox Mediators for Dye-Sensitized Solar Cells with High Photovoltage. J. Am. Chem. Soc. 2016, 138, 15087-15096. [CrossRef]

68. Freitag, M.; Giordano, F.; Yang, W.; Pazoki, M.; Hao, Y.; Zietz, B.; Grätzel, M.; Hagfeldt, A.; Boschloo, G. Copper phenanthroline as a fast and high-performance redox mediator for dye-sensitized solar cells. J. Phys. Chem. C 2016, 120, 9595-9603. [CrossRef]

69. Colombo, A.; Dragonetti, C.; Magni, M.; Roberto, D.; Demartin, F.; Caramori, S.; Bignozzi, C.A. Efficient copper mediators based on bulky asymmetric phenanthrolines for DSSCs. ACS Appl. Mater. Interfaces 2014, 6, 13945-13955. [CrossRef]

70. Freitag, M.; Teuscher, J.; Saygili, Y.; Zhang, X.; Giordano, F.; Liska, P.; Hua, J.; Zakeeruddin, S.M.; Moser, J.E.; Grätzel, M.; et al. Dye-sensitized solar cells for efficient power generation under ambient lighting. Nat. Photonics 2017, 11, 372-378. [CrossRef]

71. Cao, Y.; Liu, Y.; Zakeeruddin, S.M.; Hagfeldt, A.; Grätzel, M. Direct Contact of Selective Charge Extraction Layers Enables High-Efficiency Molecular Photovoltaics. Joule 2018, 2, 1108-1117. [CrossRef]

72. García-Rodríguez, R.; Jiang, R.; Canto-Aguilar, E.J.; Oskam, G.; Boschloo, G. Improving the mass transport of copper-complex redox mediators in dye-sensitized solar cells by reducing the inter-electrode distance. Phys. Chem. Chem. Phys. 2017, 19, 32132-32142. [CrossRef] [PubMed]

73. Wang, M.; Chamberland, N.; Breau, L.; Moser, J.E.; Humphry-Baker, R.; Marsan, B.; Zakeeruddin, S.M.; Grätzel, M. An organic redox electrolyte to rival triiodide/iodide in dye-sensitized solar cells. Nat. Chem. 2010, 2, 385-389. [CrossRef] [PubMed]

74. Burschka, J.; Brault, V.; Ahmad, S.; Breau, L.; Nazeeruddin, M.K.; Marsan, B.; Zakeeruddin, S.M.; Grätzel, M. Influence of the counter electrode on the photovoltaic performance of dye-sensitized solar cells using a disulfide/thiolate redox electrolyte. Energy Environ. Sci. 2012, 5, 6089-6097. [CrossRef]

75. Tian, H.; Yu, Z.; Hagfeldt, A.; Kloo, L.; Sun, L. Organic redox couples and organic counter electrode for efficient organic dye-sensitized solar cells. J. Am. Chem. Soc. 2011, 133, 9413-9422. [CrossRef]

76. Carli, S.; Casarin, L.; Bergamini, G.; Caramori, S.; Bignozzi, C.A. Conductive PEDOT covalently bound to transparent FTO electrodes. J. Phys. Chem. C 2014, 118, 16782-16790. [CrossRef]

77. Kamppinen, A.; Aitola, K.; Poskela, A.; Miettunen, K.; Lund, P.D. Stability of cobalt complex based dye solar cells with PEDOT and Pt catalysts and different electrolyte concentrations. Electrochim. Acta 2020, 335, 135652. [CrossRef]

78. Kim, S.J.; Kwon, J.; Nam, J.K.; Kim, W.; Park, J.H. Long-term Stability of Conducting Polymers in Iodine/iodide Electrolytes: Beyond Conventional Platinum Catalysts. Electrochim. Acta 2017, 227, 95-100. [CrossRef]

79. Biallozor, S.; Kupniewska, A. Study on poly(3,4-ethylenedioxythiophene) behaviour in I-/I2 solution. Electrochem. Commun. 2000, 2, 480-486. [CrossRef]

80. Jiang, H.; Ren, Y.; Zhang, W.; Wu, Y.; Socie, E.C.; Carlsen, B.I.; Moser, J.E.; Tian, H.; Zakeeruddin, S.M.; Zhu, W.H.; et al. Phenanthrene-Fused-Quinoxaline as a Key Building Block for Highly Efficient and Stable Sensitizers in Copper-Electrolyte-Based Dye-Sensitized Solar Cells. Angew. Chem. Int. Ed. 2020, 59, 9324-9329. [CrossRef]

81. Vlachopoulosa, N.; Zhangb, J.; Hagfeldta, A. Dye-sensitized solar cells: New approaches with organic solid-state hole conductors. Chimia 2015, 69, 41-51. [CrossRef] [PubMed]

82. Park, B.W.; Yang, L.; Johansson, E.M.J.; Vlachopoulos, N.; Chams, A.; Perruchot, C.; Jouini, M.; Boschloo, G.; Hagfeldt, A. Neutral, polaron, and bipolaron states in pedot prepared by photoelectrochemical polymerization and the effect on charge generation mechanism in the solid-state dye-sensitized solar cell. J. Phys. Chem. C 2013, 117, 22484-22491. [CrossRef]

83. Kim, Y.; Sung, Y.E.; Xia, J.B.; Lira-Cantu, M.; Masaki, N.; Yanagida, S. Solid-state dye-sensitized TiO 2 solar cells using poly(3,4ethylenedioxythiophene) as substitutes of iodine/iodide electrolytes and noble metal catalysts on FTO counter electrodes. J. Photochem. Photobiol. A Chem. 2008, 193, 77-80. [CrossRef]

84. Xia, J.; Masaki, N.; Lira-Cantu, M.; Kim, Y.; Jiang, K.; Yanagida, S. Influence of doped anions on poly(3,4-ethylenedioxythiophene) as hole conductors for iodine-free solid-state dye-sensitized solar cells. J. Am. Chem. Soc. 2008, 130, 1258-1263. [CrossRef]

85. Jang, Y.J.; Thogiti, S.; Lee, K.Y.; Kim, J.H. Long-term stable solid-state dye-sensitized solar cells assembled with solid-state polymerized hole-transporting material. Crystals 2019, 9, 452. [CrossRef] 